\title{
Hemodynamic and metabolic changes during hypercapnia with normoxia and hyperoxia using PCASL and TRUST MRI in healthy adults
}

\author{
Pieter T Deckers' ${ }^{1 *}$ (D), Alex A Bhogal ${ }^{2 * *} \mathbb{D}$, \\ Mathijs BJ Dijsselhof ${ }^{2,3}$ (D), Carlos C Faraco ${ }^{4}$, Peiying Liu ${ }^{5}$, \\ Hanzhang Lu ${ }^{5}$, Manus J Donahue ${ }^{4}$ and Jeroen C.W Siero ${ }^{2,6}$ (D)
}

Journal of Cerebral Blood Flow \&

Metabolism

$4 I$ (II) I-15

(C) The Author(s) 2021

(c) (i)

Article reuse guidelines: sagepub.com/journals-permissions DOI: $10.1|177 / 027| 678 \times 2 \mid 1064572$ journals.sagepub.com/home/jcbfm @SAGE

\begin{abstract}
Blood oxygenation level-dependent (BOLD) or arterial spin labeling (ASL) MRI with hypercapnic stimuli allow for measuring cerebrovascular reactivity (CVR). Hypercapnic stimuli are also employed in calibrated BOLD functional MRI for quantifying neuronally-evoked changes in cerebral oxygen metabolism $\left(\mathrm{CMRO}_{2}\right)$. It is often assumed that hypercapnic stimuli (with or without hyperoxia) are iso-metabolic; increasing arterial $\mathrm{CO}_{2}$ or $\mathrm{O}_{2}$ does not affect $\mathrm{CMRO}_{2}$. We evaluated the null hypothesis that two common hypercapnic stimuli, ' $\mathrm{CO}_{2}$ in air' and carbogen, are isometabolic. TRUST and ASL MRI were used to measure the cerebral venous oxygenation and cerebral blood flow (CBF), from which the oxygen extraction fraction (OEF) and $\mathrm{CMRO}_{2}$ were calculated for room-air, ' $\mathrm{CO}_{2}$ in air' and carbogen. As expected, $\mathrm{CBF}$ significantly increased $\left(9.9 \% \pm 9.3 \%\right.$ and $12.1 \% \pm 8.8 \%$ for ' $\mathrm{CO}_{2}$ in air' and carbogen, respectively). $\mathrm{CMRO}_{2}$ decreased for ' $\mathrm{CO}_{2}$ in air' $(-13.4 \% \pm 13.0 \%, \mathrm{p}<0.0 \mathrm{I})$ compared to room-air, while the $\mathrm{CMRO}_{2}$ during carbogen did not significantly change. Our findings indicate that ' $\mathrm{CO}_{2}$ in air' is not iso-metabolic, while carbogen appears to elicit a mixed effect; the $\mathrm{CMRO}_{2}$ reduction during hypercapnia is mitigated when including hyperoxia. These findings can be important for interpreting measurements using hypercapnic or hypercapnic-hyperoxic (carbogen) stimuli.
\end{abstract}

\section{Keywords}

Carbogen, cerebral metabolic rate of oxygen, cerebral venous oxygenation, hypercapnia, hyperoxia

Received 4 May 202I; Revised 6 October 202I; Accepted 7 November 2021

\section{Introduction}

Advanced MRI techniques provide an avenue to image functional parameters such as oxygen extraction fraction $(\mathrm{OEF})$, cerebral blood flow (CBF), cerebral blood volume $(\mathrm{CBV})$, and the cerebral metabolic rate of oxygen consumption $\left(\mathrm{CMRO}_{2}\right)$. Thereby, these MRI techniques can provide metabolic and hemodynamic metrics similar to those obtained using PET, but noninvasively and at higher spatial and temporal resolution. One such approach is calibrated fMRI (or calibrated BOLD) that can be used to scale task-related BOLD fMRI responses to the underlying $\mathrm{CMRO}_{2}$ changes. ${ }^{1}$ This technique has found applications to examine metabolic demands associated with functional tasks but also ageing and brain disease. ${ }^{2-5}$
'Department of Neurosurgery, University Medical Center Utrecht, Utrecht, Netherlands

${ }^{2}$ Department of Radiology, Center for Image Sciences, University Medical Center Utrecht, Utrecht, Netherlands

${ }^{3}$ Department of Radiology and Nuclear Medicine, Amsterdam Neuroscience, Amsterdam UMC (location VUmc), Amsterdam, Netherlands

${ }^{4}$ Radiology and Radiological Sciences, Vanderbilt University Medical Center, Nashville, Tennessee, USA

${ }^{5}$ Department of Radiology, Johns Hopkins University School of Medicine, Baltimore, Maryland, USA

${ }^{6}$ Spinoza Centre for Neuroimaging, Amsterdam, Netherlands

*These authors contributed equally to this work.

\section{Corresponding author:}

Pieter T Deckers, Department of Neurosurgery, University Medical Center Utrecht, Heidelberglaan 100, 3584 CX, Utrecht, the Netherlands. Email: P.T.Deckers@umcutrecht.nl 
The BOLD calibration models rely on measurements of both BOLD and CBF signal changes during either hypercapnic respiratory challenges or a combination of hypercapnic-hyperoxic challenges. ${ }^{6-9}$ Modulations in arterial gas tensions evoke predictable physiological responses that are used to contextualize fMRI signal changes. ${ }^{10-13}$ In short, hypercapnia is a potent vasodilator that leads to significant increases in $\mathrm{CBV}, \mathrm{CBF}$, and accompanying increases in venous blood oxygenation, while hyperoxia is thought to only modulate the blood oxygenation through plasmadissolved $\mathrm{O}_{2}$ and increased hemoglobin $(\mathrm{Hb})$ bound $\mathrm{O}_{2}$. This dual-action convolutes the net hemodynamic and metabolic response through its influence on the oxygen saturation curve via the Bohr effect (i.e. how $\mathrm{CO}_{2}$ affects the binding affinity of $\mathrm{Hb}$ for $\mathrm{O}_{2}$ ) and the Haldane effect (i.e. how $\mathrm{O}_{2}$ affects the binding affinity of $\mathrm{Hb}$ for $\mathrm{CO}_{2}$ ). An original assumption during the early development of the calibration model was that increasing arterial levels of $\mathrm{CO}_{2}$ and $\mathrm{O}_{2}$ had a negligible effect on neuronal metabolism and thus $\mathrm{CMRO}_{2} .{ }^{4}$ This notion has since been challenged, and correction methods have been devised to account for the possibility that changing arterial $\mathrm{O}_{2}$ or $\mathrm{CO}_{2}$ tensions do indeed modulate neuronal functioning and $\mathrm{CMRO}_{2}{ }^{9,11-18}$ Previous simulation work on calibrated BOLD models has reported that for non iso-metabolic hypercapnic challenges for calibration, one can find a significant error in estimating the basal $\mathrm{OEF}$ and activation-induced $\mathrm{CMRO}_{2}$ changes in calibrated BOLD studies. ${ }^{10,19,20}$ Correction methods for situations in which arterial $\mathrm{O}_{2}$ and $\mathrm{CO}_{2}$ tensions change simultaneously have not yet been adopted.

Quantitative assessment of venous oxygenation $\left(\mathrm{Y}_{\mathrm{v}}\right)$, while considering the combined effects of changing $\mathrm{CBF}$ and $\mathrm{OEF}$, provides an avenue to examine the iso-metabolic assumptions associated with respiratory stimuli via inferred changes in $\mathrm{CMRO}_{2}$. This can be performed non-invasively using a technique known as $\mathrm{T}_{2}$-Relaxation-Under-Spin-Tagging (TRUST) MRI. ${ }^{21}$ Direct knowledge of the effects that changing arterial $\mathrm{O}_{2}$ and $\mathrm{CO}_{2}$ tensions have on $\mathrm{CMRO}_{2}$ has widespread implications. For instance, appropriate corrections can improve the accuracy of fMRI techniques for neuroscientific applications, refine BOLD signal models that simulate magnetic susceptibility effects under different physiological conditions, ${ }^{22-24}$ and improve the interpretation of CVR for clinical applications via a more robust understanding of concomitant $\mathrm{CMRO}_{2}$ changes. ${ }^{25-28}$

The use of respiratory challenges during MRI in various patient populations is becoming more widespread. In many of these cases, the pathophysiology of neurological and cerebrovascular disease leads to altered cerebral metabolism. With this in mind, it becomes essential to identify co-factors that influence cerebral metabolism and are accounted for accordingly. Therefore, this study aimed to evaluate the assumption that hypercapnic stimuli applied in healthy adults are iso-metabolic. To achieve this, we used ASL and TRUST MRI for measures of global CBF and $Y_{v}$ to compare measures of $\mathrm{CMRO}_{2}$ under two commonly used hypercapnic conditions (' $\mathrm{CO}_{2}$ in air': $5 \%$

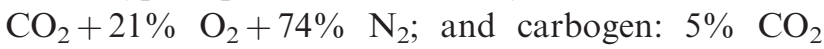
and $95 \% \mathrm{O}_{2}$ ). The $\mathrm{CMRO}_{2}$ value for each condition was calculated and compared with the $\mathrm{CMRO}_{2}$ value obtained during the breathing of medical air (referred to as 'room-air').

\section{Methods}

\section{Volunteer demographics}

Healthy volunteers $(n=10 ; 3 F / 7 \quad M ;$ age $=29.4 \pm$ 3.4 years) provided informed, written consent following the ethical standards of the Vanderbilt University Institutional Review Board, the Vanderbilt University Human Research Protection Program, as well as with the Helsinki Declaration of 1975 (and as revised in 1983). All components of this study were performed in compliance with the Health Insurance Portability and Accountability Act. All study components were reviewed and approved by the local Institutional Review Board (IRB Study 111116).

\section{$M R I$ experiment}

All MRI measurements were performed at $3.0 \mathrm{~T}$ (Philips Healthcare, Best, The Netherlands). For a schematic overview of the MRI experiment see Figure 1. Participants were fitted with a nasal cannula (Salter Labs, Arvin, CA, USA, no. 4000) to monitor the end-tidal partial pressure of $\mathrm{CO}_{2}\left(\mathrm{pEtCO}_{2}\right)$ and a custom non-rebreathing face mask (Salter Labs, no. 8005) for gas stimulus administration. The masks were close-fitting and covered the nose and mouth. Elastic straps were used to reduce leakage. Gases were delivered from compressed cylinders outside the scan room and administered at $12 \mathrm{~L} / \mathrm{min}$. This flow rate was optimized in preliminary studies and was found to provide sufficient gas delivery in the presence of potential small leaks in the mask, while also maintaining comfort. Physiological monitoring was performed using an Invivo Research (Gainesville, FL, USA, 3150 MRI) monitor and a remote monitor (Millenia Vital System, Gainsville, FL, USA, 3115 MVS). Monitored parameters included partial pressure of end-tidal $\mathrm{CO}_{2}\left(\mathrm{pEtCO}_{2}\right.$ in $\mathrm{mmHg}$ ), and peripheral arterial oxygenation $\left(\mathrm{Y}_{\mathrm{a}}\right)$. The repeatability of this setup 
has been reported previously ${ }^{29}$ and a similar setup is used in a previously reported work. ${ }^{24}$

Venous oxygenation $\left(Y_{v}\right)$ MRI measurements were performed on the occipital part of the superior sagittal sinus using TRUST MRI $(\mathrm{TR}=3 \mathrm{~s}, \mathrm{TI}=1.2 \mathrm{~s}$, voxel size $=3.4 \times 3.4 \times 5 \mathrm{~mm}^{3}$, four $\mathrm{T}_{2}$ weightings (effective TEs: $0,40,80$, and $160 \mathrm{~ms}$ ), with a $\tau_{\mathrm{CPMG}}=10 \mathrm{~ms}$, and 3 averages per $T_{2}$ weighting yielding a total scan duration of $1 \mathrm{~min} 12 \mathrm{~s} .{ }^{30,31} \mathrm{CBF}$ measurements were performed using pCASL MRI with a multi-slice echo-planar imaging readout. Acquisition parameters were post-label delay $(\mathrm{PLD})=1.7 \mathrm{~s}$, label duration $=$ $1.5 \mathrm{~s}, \quad \mathrm{TR} / \mathrm{TE}=3900 / 13.1 \mathrm{~ms}, \quad$ measurements $=13$, field-of-view $=240 \times 240 \times 119 \mathrm{~mm}^{3}$, spatial resolution $=3 \times 3 \times 7 \mathrm{~mm}^{3}$, slices $=17$, SENSE factor $=1.8$. The TRUST scan was repeated once for the hypercapnic breathing conditions but was only performed once for the room-air conditions. TRUST and pCASL data were sequentially acquired throughout the following paradigm: 3 min room-air ('room-air 1') $-\sim 4$ min of $5 \% \mathrm{CO}_{2}$ balanced with medical-grade atmospheric air $\left(5 \% \mathrm{CO}_{2} / 21 \% \mathrm{O}_{2} / 74 \% \mathrm{~N}_{2} ;{ }^{\prime} \mathrm{CO}_{2}\right.$ in air': as described earlier $^{24}$ ) $-3 \mathrm{~min}$ room-air ('room-air 2') - 4 min carbogen $\left(5 \% \mathrm{CO}_{2}, 95 \% \mathrm{CO}_{2}\right.$; Figure 1). For each hypercapnic breathing condition, the two $Y_{\mathrm{v}}$ values were first estimated from the two TRUST measurements and subsequently averaged into a single $\mathrm{Y}_{\mathrm{v}}$ value per condition. In addition, a calibration $\mathrm{M}_{0}$ scan was acquired for both groups for CBF quantification, using identical acquisition geometry as the pCASL scan, but with TR $=15 \mathrm{~s}$, and the spin labeling pulse train turned off. The order of ' $\mathrm{CO}_{2}$ in air' and carbogen and the TRUST and pCASL scan was randomized between subjects and time $(\sim 30 \mathrm{~s})$ was allowed for $\mathrm{pEtCO}_{2}$ and $\mathrm{Y}_{\mathrm{v}}$ to equilibrate between the two hypercarbic conditions.

\section{Analysis}

CBF quantification. CBF quantification was performed using FSL BASIL; ${ }^{32}$ pCASL label and control images were pair-wise subtracted, and a single-compartment kinetic model was applied to the data using tissueblood partition coefficient of water $\lambda=0.9 \mathrm{ml} / \mathrm{g}$ and pCASL labeling efficiency $\alpha=0.85 .{ }^{33}$ Slice time correction was incorporated by using slice-specific PLD values. For equilibrium blood water magnetization, the calibration $\mathrm{M}_{0}$ image was used. An arterial blood water $\mathrm{T}_{1}\left(\mathrm{~T}_{1 \mathrm{a}}\right)$ reduction from $1.65 \mathrm{~s}$ (used for the (a)

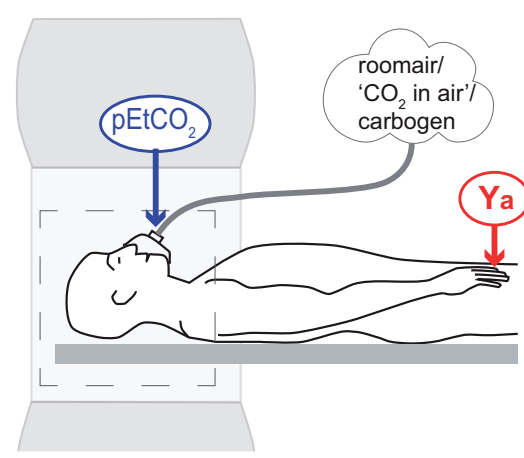

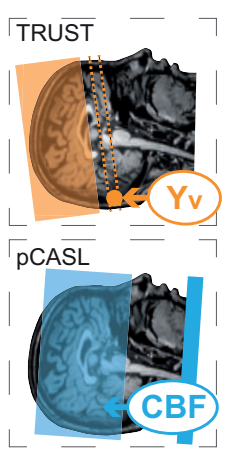

(b)

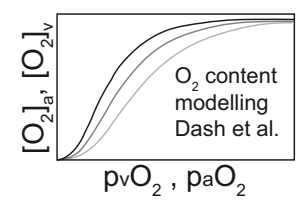

$\left[\mathrm{O}_{2}\right]_{\mathrm{a}}=\mathrm{Ya} \cdot \mathrm{Ch}+\mathrm{paO}_{2} \cdot \mathrm{Cd}$

$\left[\mathrm{O}_{2}\right]_{v}=\mathrm{Y}_{\mathrm{v}} \cdot \mathrm{Ch}+\mathrm{pvO}_{2} \cdot \mathrm{Cd}$

$\mathrm{OEF}=\left(\left[\mathrm{O}_{2}\right]_{\mathrm{a}}-\left[\mathrm{O}_{2}\right]_{\mathrm{v}}\right) /\left[\mathrm{O}_{2}\right]_{\mathrm{a}}$

$\mathrm{CMRO}_{2}=\mathrm{CBF} \cdot\left(\left[\mathrm{O}_{2}\right]_{\mathrm{a}}-\left[\mathrm{O}_{2}\right]_{\mathrm{v}}\right)$

(c)

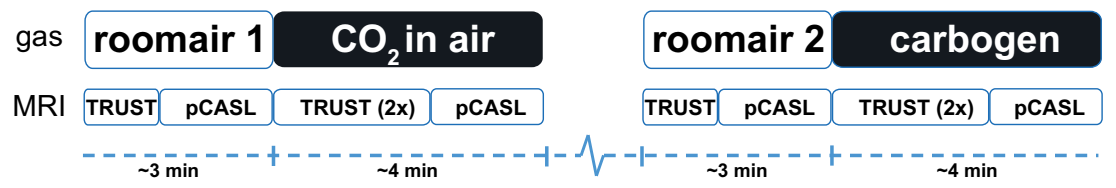

Figure I. Schematic overview of the experimental design. a) the subject in the MRI with the three different inspired gases and the physiological measurements of $\mathrm{pEtCO}_{2}$ (purple) from the breathing mask, arterial oxygenation $\mathrm{Y}_{\mathrm{a}}$ (red) from a pulse-oximeter, venous oxygenation $Y_{v}$ (orange), and CBF (blue). Conceptual planning for cerebral venous oxygenation ( $Y_{v}$ ) using T2-relaxation-under-

spin-tagging (TRUST) MRI is depicted by the orange region, where the dotted lines represent the measurement plane and the circle the location of the occipital part of the superior sagittal sinus. Whole-brain CBF values were acquired using a pseudo-continuous arterial spin labeling PCASL sequence (planning depicted in blue). b) The $\left[\mathrm{O}_{2}\right]_{\mathrm{a}},\left[\mathrm{O}_{2}\right]_{v}, \mathrm{PaO}_{2}$, and $\mathrm{p}_{v} \mathrm{O}_{2}$ values were calculated using a physiological blood oxygen content model (Dash et al.) and were applied for computing $\mathrm{CMRO}_{2}$ and OEF using the formulas shown. c) Experimental design of the gas delivery paradigm. The dashed blue line represents the rest period $(\sim 30 \mathrm{~s})$ given to allow pEtCO 2 and $Y_{v}$ to equilibrate. The order of ' $\mathrm{CO}_{2}$ in air' and carbogen conditions and the TRUST and PCASL scan was randomized between subjects. 
normoxic conditions) to $1.49 \mathrm{~s}$ (hyperoxic conditions) was used to account for hyperoxia-dependent changes related to the carbogen condition, as reported previously. ${ }^{34}$

For tissue $T_{1}$ and arterial (bolus) arrival time, gray matter values (GM) were used in BASIL FSL, $1.3 \mathrm{~s}^{35}$ and $1.3 \mathrm{~s}^{29,36}$ for pCASL, respectively, including a GM arrival time reduction of $5 \%$ for the hypercapnic conditions. ${ }^{29,36}$ Global CBF was estimated using subjectspecific brain tissue segmentation masks and associated tissue probability maps of GM and white matter (WM). We focused on global CBF as opposed to solely GM CBF as the TRUST measurement for $\mathrm{Y}_{\mathrm{v}}(\%)$ also samples a global value. Tissue segmentation was performed on the $\mathrm{M}_{0}$ image that exhibited adequate GM and WM contrast using FSL FAST. ${ }^{37}$ The global CBF estimation excluded subarachnoidal space and ventricular cerebral spinal fluid (CSF), cerebellum and brainstem regions. CSF regions were removed using the subject-specific segmentations masks from FSL FAST, the cerebellum and brainstem regions were removed using the MNI Structural Atlas and the Harvard-Oxford Structural Atlas ${ }^{38}$ MNI based (Montreal Neurological Institute) ROIs, respectively, available in FSL. ${ }^{39}$ Segmentation and atlas ROIs were constrained by the subject's whole-brain mask obtained from the $\mathrm{M}_{0}$ image using FSL BET. ${ }^{40}$ Note that GM values were used for the tissue $T_{1}$ and arterial arrival time for all voxels using FSL BASIL for the $\mathrm{CBF}$ quantification. However, these values are not appropriate for WM CBF included in this study to obtain global $\mathrm{CBF}$ and can lead to an underestimation for WM CBF (See Supplementary Material Figure 1). We computed a correction factor for WM CBF using the WM tissue $\mathrm{T}_{1}$ and arterial arrival time, $0.84 \mathrm{~s}^{35}$ and $1.7 \mathrm{~s},{ }^{36}$ respectively, as recently reported by Juttakonda et al. ${ }^{36}$ (see Supplementary Material for computation). Average global CBF was recomputed by summing the GM and WM CBF maps weighted by the tissue probability maps and the WM correction factor for WM $\quad(1.20$, see Supplementary Material and Supplementary Figure 1). Voxels with outlier CBF values were discarded for absolute $\mathrm{CBF}$ values larger than two standard deviations above the mean global $\mathrm{CBF}$, i.e. $\left|\mathrm{CBF}_{\text {voxel }}\right|>$ mean (global $\left.\mathrm{CBF}\right) \pm 2$ std (global $\mathrm{CBF}$ ). To visualize the group average $\mathrm{CBF}$ map results, the subjects' $\mathrm{CBF}$ maps were first spatially normalized to the standard MNI $2 \mathrm{~mm}^{3}$ stereotaxic space using FSL FLIRT with 12 degrees of freedom affine registration and sinc interpolation. ${ }^{41}$ The subject averaged pCASL control image was used as an intermediate step.

CMRO2 and OEF estimation. Calculation of $Y_{v}$ from the TRUST MRI data was done using the method described previously. ${ }^{13}$ For the repeated scans, i.e. for the ' $\mathrm{CO}_{2}$ in air' and 'carbogen' conditions, the fitted $\mathrm{Y}_{\mathrm{v}}$ values were averaged. To account for the plasma dissolved $\mathrm{O}_{2}$ present during the hyperoxic condition, we computed the total arterial $\mathrm{O}_{2}$ content $\left(\left[\mathrm{O}_{2}\right]_{\mathrm{a}}\right)$, venous $\mathrm{O}_{2}$ content $\left(\left[\mathrm{O}_{2}\right]_{\mathrm{v}}\right)$, and partial pressure of venous $\mathrm{O}_{2}$ $\left(\mathrm{p}_{\mathrm{v}} \mathrm{O}_{2}\right)$ using the physiological model by Dash et al. ${ }^{42}$ that models the blood $\mathrm{O}_{2}$ and $\mathrm{CO}_{2}$ content by generating the hemoglobin- $\mathrm{O}_{2}$ and $\mathrm{CO}_{2}$ dissociation (saturation) curve and computing the plasma-dissolved $\mathrm{O}_{2}{ }^{24,42}$ The model takes into account the Bohr effect for which $\mathrm{O}_{2}$ binding to hemoglobin is inversely related to the presence of $\mathrm{CO}_{2}$ by using the measured $\mathrm{pEtCO}_{2}$ (see Table 1). This will yield subject-specific and breathing condition-specific hemoglobin $\mathrm{O}_{2}$ saturation curves, dependent on blood $\mathrm{pO}_{2}$ and $\mathrm{pCO}_{2}$. We will show the $\mathrm{O}_{2}$ saturation curve by Dash et al. ${ }^{42}$ and the commonly used saturation curve by Severinghaus (1), that depends only on the $\mathrm{pO}_{2}:^{43}$

$$
Y_{(\%)}=\left(\frac{1}{\frac{1}{p O_{2}^{3}+150 \cdot p O_{2}} \cdot 23400+1}\right) \cdot 100 \%
$$

The partial pressure of alveolar $\mathrm{O}_{2}\left(\mathrm{p}_{\mathrm{A}} \mathrm{O}_{2}\right)$ was assumed $104 \mathrm{mmHg}$ respectively for the ' $\mathrm{CO}_{2}$ in air' and room-air conditions. ${ }^{44}$ For these normoxic conditions, alveolar, $\mathrm{p}_{\mathrm{A}} \mathrm{O}_{2}$, was converted to arterial $\mathrm{O}_{2}$ pressure $\left(\mathrm{p}_{\mathrm{a}} \mathrm{O}_{2}\right)$ using the alveolar-arterial $\mathrm{O}_{2}$ pressure gradient, which depends on the $\mathrm{p}_{\mathrm{A}} \mathrm{O}_{2}$ and age. ${ }^{12}$ For the carbogen condition, we used the values from previous reports on direct measurements of arterial partial pressure $\mathrm{PaO}_{2}$ for carbogen in healthy subjects that used an arterial line during PET examination:

$\mathrm{p}_{\mathrm{a}} \mathrm{O}_{2, \text { carbogen }}=460 \mathrm{mmHg} .{ }^{45,46}$ The venous partial pressure of $\mathrm{CO}_{2}\left(\mathrm{p}_{\mathrm{V}} \mathrm{CO}_{2}\right)$ was offset by $+5 \mathrm{mmHg}$ compared to the measured $\mathrm{pEtCO}_{2}{ }^{44}$ The $\mathrm{p}_{\mathrm{v}} \mathrm{CO}_{2}$ estimates are needed to incorporate the Bohr effect; when locally $\mathrm{CO}_{2}$ partial pressure is increased, the hemoglobin affinity for $\mathrm{O}_{2}$ is decreased, which we can expect in peripheral and cerebral tissue and under hypercapnic conditions resulting in a right shift of the $\mathrm{HbO}_{2}$ curve. The mathematical model put forward by Dash et al. ${ }^{42}$ incorporates the $\mathrm{p}_{\mathrm{v}} \mathrm{CO}_{2}$ in the $\mathrm{K}_{\mathrm{Hb}} \mathrm{O}_{2}$ factor, the apparent equilibrium constant for binding $\mathrm{O}_{2}$ to hemoglobin. The $\mathrm{K}_{\mathrm{Hb}} \mathrm{O}_{2}$ factor itself is a complex equation describing the binding kinematics of $\mathrm{O}_{2}$ to hemoglobin (see equations 1a,b and 3a,b in Dash et al. ${ }^{42}$ ) Note that changes in $\mathrm{pH}$, temperature, and 2,3 -DPG will also shift the $\mathrm{HbO}_{2}$ curve and can in principle be incorporated into the physiological model. Hematocrit (Hct) values of 0.42 for males and 0.4 for females were assumed.

OEF and $\mathrm{CMRO}_{2}$ were computed using formulas (2) and (3) using equations (4) and (5) for the 


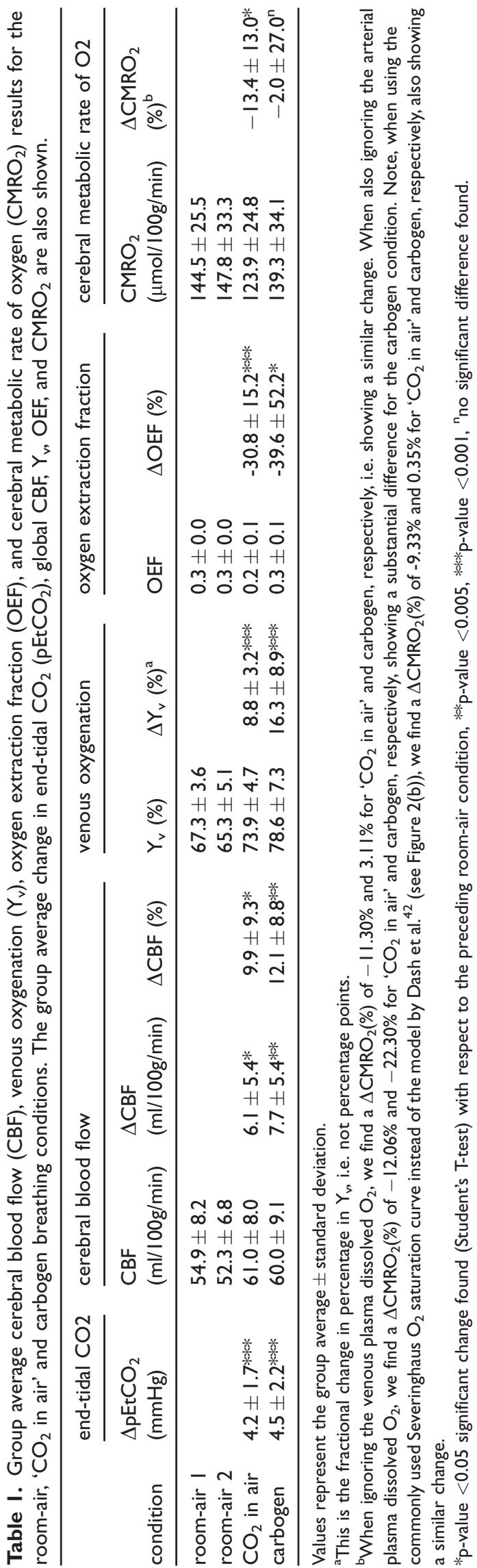

calculation of $\left[\mathrm{O}_{2}\right]_{\mathrm{a}}$ and $\left[\mathrm{O}_{2}\right]_{\mathrm{v}}$, i.e. the sum of the hemoglobin bound $\mathrm{O}_{2}$ and plasma dissolved $\mathrm{O}_{2}$ content.

$$
\begin{gathered}
\mathrm{OEF}=\frac{\left[\mathrm{O}_{2}\right]_{a}-\left[\mathrm{O}_{2}\right]_{v}}{\left[\mathrm{O}_{2}\right]_{a}} \\
\mathrm{CMRO}_{2}=\mathrm{CBF} \cdot\left(\left[\mathrm{O}_{2}\right]_{a}-\left[\mathrm{O}_{2}\right]_{v}\right)
\end{gathered}
$$

with

$$
\left[O_{2}\right]_{a}=Y_{a} \cdot C_{h}+p_{a} O_{2} \cdot C_{d}
$$

and

$$
\left[O_{2}\right]_{v}=Y_{v} \cdot C_{h}+p_{v} O_{2} \cdot C_{d}
$$

Constants $\mathrm{C}_{\mathrm{h}}\left(912 \mu \mathrm{mol} \mathrm{O}_{2} / 100 \mathrm{ml}\right.$ blood for a Hct of 0.45 , but adjusted for the assumed Hct values for male and female subjects $\left.{ }^{42}\right)$ and $\mathrm{C}_{\mathrm{d}}\left(0.138 \mu \mathrm{mol} \mathrm{O}_{2} /\right.$ $100 \mathrm{ml} \mathrm{blood} / \mathrm{mmHg} \mathrm{p}_{\mathrm{a}} \mathrm{O}_{2}$ ) are the hemoglobin $\mathrm{O}_{2}$ carrying capacity and blood plasma $\mathrm{O}_{2}$ dissolving capacity, respectively. ${ }^{13}$ Dash et al. 2016 model $^{42}$ can be downloaded (JSIM and Matlab code) from the NSR Physiome Project repository that contains integrative and descriptive models on human physiology: www. imagwiki.nibib.nih.gov/physiome/jsim/models/webmo del/NSR/SHbO2CO2Dash2016/.

Effect of arterial blood water TIa on CBF and $\mathrm{CMRO}_{2}$ quantification. The choice of arterial blood water $\mathrm{T}_{1 \mathrm{a}}$ can have a considerable impact on the absolute $\mathrm{CBF}$ and $\mathrm{CMRO}_{2}$ quantification, and especially during hyperoxic conditions where substantial $\mathrm{T}_{1 \mathrm{a}}$ changes can be expected. ${ }^{34}$ Therefore, we performed a sensitivity analysis to investigate the influence of varying $T_{1 a}$ on $\mathrm{CBF}$ and $\mathrm{CMRO}_{2}$ quantification, caused by for instance hyperoxia but also Hct variations (see Supplementary Figure 2).

In addition, we investigated whether different $T_{1 a}$ scenarios impacted the $\mathrm{CBF}, \triangle \mathrm{CBF}$, and importantly the $\mathrm{CMRO}_{2}$ and $\triangle \mathrm{CMRO}_{2}$ quantification, using commonly used values at $3 \mathrm{~T}$ for normoxic $\left(\mathrm{T}_{1, \mathrm{NO}}\right)$ and hyperoxic $\left(\mathrm{T}_{1}\right.$, но) conditions. For the normoxic conditions, $T_{1 a}$ values were used as reported by Lu et al. ${ }^{47}\left(\mathrm{~T}_{1, \mathrm{NO}}=1.65 \mathrm{~s}\right.$, bovine blood, recommended ASL Whitepaper value ${ }^{48}$ ) by Pilkinton et al. ${ }^{49}\left(\mathrm{~T}_{1, \mathrm{NO}}=1.669 \mathrm{~s}\right.$, rat blood $)$ commonly used in calibrated BOLD studies, ${ }^{50}$ and the recently modelled and measured value by Li et al. ${ }^{51,52}$ for human blood $\left(\mathrm{T}_{1, \mathrm{NO}}=1.898 \mathrm{~s}\right.$, human blood $)$.

For the hyperoxic condition (assuming a $\mathrm{p}_{\mathrm{a}} \mathrm{O}_{2}=460 \mathrm{mmHg}$ for carbogen), we used the values 
as reported by Siero et al., ${ }^{34} \mathrm{~T}_{1, \mathrm{HO}}=1.49 \mathrm{~s}$ based on $\mathrm{T}_{1}$, $\mathrm{NO}=1.65 \mathrm{~s}$ (Scenario I), the reported hyperoxic $\mathrm{T}_{1 \mathrm{a}}$ relativity by $\mathrm{Ma}$ et al., ${ }^{53}$ yielding a $\mathrm{T}_{1, \mathrm{HO}}=1.472 \mathrm{~s}$ based on $\mathrm{T}_{1, \mathrm{NO}}=1.65 \mathrm{~s}$ (Scenario II), the report by Pilkinton et al., ${ }^{49} \mathrm{~T}_{1, \mathrm{HO}}=1.527 \mathrm{~s}$ based on $\mathrm{T}_{1, \mathrm{NO}}=1.669 \mathrm{~s}$ (Scenario III), and the model by $\mathrm{Li}$ et al. ${ }^{51}$ where we incorporated the hyperoxic relaxivity by $\mathrm{Ma}$ et al., ${ }^{53}$ yielding a $\mathrm{T}_{1, \mathrm{HO}}=1.743 \mathrm{~s}$ based on $\mathrm{T}_{1, \mathrm{NO}}=1.898 \mathrm{~s}$ by Li et al. ${ }^{51}$ (Scenario IV). In summary, four scenarios with different $T_{1, \mathrm{NO}}$ and $\mathrm{T}_{1, \mathrm{HO}}$ combinations were used to assess the effect on the CBF, $\triangle \mathrm{CBF}, \mathrm{CMRO}_{2}$ and $\triangle \mathrm{CMRO}_{2}$ quantification (see Supplementary Figure 3).

Statistical analysis. Statistical analysis was performed to assess significant differences in the change in hemodynamic parameters for each separate hypercapnic condition (' $\mathrm{CO}_{2}$ in air' versus preceding room-air and carbogen versus preceding room-air) using Student's T-test in SPSS Statistics version 26 (IBM Business Analytics, New York, USA). The distribution of the data was visually checked with histograms and Q-Q plots, and formally with the Kolmogorov-Smirnov test. A p-value $<0.05$ was considered significant.

\section{Results}

All ten subjects completed the study with no reported adverse effects. All data were normally distributed. The $\mathrm{pEtCO}$ averaged across subjects increased significantly $(\mathrm{p}<0.001)$ from the 'room-air 1' $(45.0 \pm 3.6 \mathrm{mmHg})$ to the ' $\mathrm{CO}_{2}$ in air' conditions $(49.2 \pm 2.7 \mathrm{mmHg})$ and from the 'room-air 2' $(43.7 \pm 3.6 \mathrm{mmHg})$ to the carbogen $(48.1 \pm 3.0 \mathrm{mmHg})$ conditions. The change in $\mathrm{pEtCO}_{2}(\Delta \mathrm{pEtCO})$ is shown in Table 1 for all subjects. Arterial oxygenation $\left(\mathrm{Y}_{\mathrm{a}}\right)$ for 'room-air 1', 'room-air 2 ', ' $\mathrm{CO}_{2}$ in air' and 'carbogen' conditions were $98.2 \pm$ $0.6 \%, \quad 98.4 \pm 0.4 \%, \quad 98.5 \pm 0.6 \%$ and $98.9 \pm 0.4 \%$, respectively. Relative to the corresponding room-air conditions, $\mathrm{Y}_{\mathrm{a}}$ increased less for ' $\mathrm{CO}_{2}$ in air' than for the carbogen $(\mathrm{p}=0.01)$ condition.

Figure 2(a) shows the hemoglobin bound $\mathrm{O}_{2}$ curve and the plasma dissolved $\mathrm{O}_{2}$ curve as a function of the partial pressure of $\mathrm{O}_{2}\left(\mathrm{pO}_{2}\right)$. These curves were used to show the range of $\mathrm{HbO}_{2}$ and plasma $\mathrm{O}_{2}$, for both the arterial and venous networks, using the subject-specific $\mathrm{Y}_{\mathrm{v}}$ and $\mathrm{P}_{\mathrm{a}} \mathrm{O}_{2}$ values for all three breathing conditions. The curves were computed using the Dash et al. ${ }^{42}$ physiological model, using the (assumed) Hct and measured $\mathrm{pEtCO}_{2}$ as the input for each subject, and then averaged across subjects. Note the high $\mathrm{p}_{\mathrm{a}} \mathrm{O}_{2}$ for the carbogen condition and the associated plasma dissolved $\mathrm{O}_{2}$ content; venous plasma dissolved $\mathrm{O}_{2}$ plays a negligible role in the arteriovenous difference to compute $\mathrm{CMRO}_{2}$. Figure 2(b) depicts a selected portion of the $\mathrm{O}_{2}$ saturation curve derived from the Severinghaus equation (dotted light-blue), and the model by Dash et $\mathrm{al}^{42}$ that incorporates the dependencies on $\mathrm{pCO}_{2}$ and Hct, as well as the 'right shift' that occurs under hypercapnia due to the Bohr effect. Note that the effect of the latter is negligible for the arteriovenous $\mathrm{O}_{2}$ difference for all hypercapnic breathing conditions. In addition, the effect of hyperoxia during carbogen inhalation did not notably increase the venous blood $\mathrm{CO}_{2}$ content through the Haldane effect $(<1 \%$, data not shown). The blood $\mathrm{CO}_{2}$ content is mostly in the form of bicarbonate and an order of magnitude less as dissolved $\mathrm{CO}_{2}$ and hemoglobin bound $\mathrm{CO}_{2}$. See Figure 3 for the values of the blood $\mathrm{O}_{2}$ content and the arteriovenous difference for all breathing conditions.

The group average global CBF maps showed similar increases in $\mathrm{CBF}$ during the ' $\mathrm{CO}_{2}$ in air' and carbogen conditions compared to room-air (Figure 4). Significant changes in global CBF, $\mathrm{Y}_{\mathrm{V}}$ and $\mathrm{OEF}$ for ' $\mathrm{CO}_{2}$ in air' and carbogen were observed (Figure 5, Table 1). The percentage CBF increase for ${ }^{\circ} \mathrm{CO}_{2}$ in air' and carbogen was $9.9 \pm 9.3 \%$ and $12.1 \pm 8.8 \%$, respectively. The absolute $\mathrm{CBF}$ increase per $\mathrm{mmHg}$ $\mathrm{pEtCO}_{2}$ for ' $\mathrm{CO}_{2}$ in air' and carbogen were $1.7 \pm 1.5$ and $\quad 2.8 \pm 3.2 \mathrm{ml} / 100 \mathrm{~g} / \mathrm{min} / \mathrm{mmHg}$, respectively. Relative and absolute CBF changes between each hypercapnic condition were not statistically significant (Table 1). Compared to the room-air condition, venous oxygenation $\mathrm{Y}_{\mathrm{v}}$ increased by $8.8 \pm 3.2 \%(\mathrm{p}<0.001)$ for the ' $\mathrm{CO}_{2}$ in air' condition. As expected, a more considerable increase in $\mathrm{Y}_{\mathrm{v}}$ was observed for the carbogen condition $(16.3 \pm 8.9 \%, \mathrm{p}<0.001)$ due to the hyperoxic gas mixture in addition to the increased blood flow. No significant differences in $\mathrm{OEF}$ were found between ' $\mathrm{CO}_{2}$ in air' and carbogen conditions; the reduction in OEF was $30.8 \pm 15.2 \%(\mathrm{p}<0.0001)$ and $39.6 \pm$ $52.2 \%(\mathrm{p}<0.05)$ respectively compared to room-air (see Table 1). Note that the amount of plasma dissolved $\mathrm{O}_{2}$ was included in the computation of the OEF and $\mathrm{CMRO}_{2}$ for both conditions (see Methods).

Significant $\mathrm{CMRO}_{2}$ changes were only observed for the ' $\mathrm{CO}_{2}$ in air' condition, showing a decrease of $13.4 \pm 13.0 \% \quad(\mathrm{p}<0.01)$ (see Table 1$). \Delta \mathrm{CMRO}_{2}$ did not significantly change for the carbogen condition, $-2.0 \pm 27.0 \%$. Note, when using the commonly used Severinghaus $\mathrm{O}_{2}$ saturation curve instead of the model by Dash et al. ${ }^{42}$ (see Figure 2(b)), we find a $\triangle \mathrm{CMRO}_{2}(\%)$ of $-10.4 \%$ and $0.3 \%$ for ' $\mathrm{CO}_{2}$ in air' and carbogen, respectively, also showing a similar change. When ignoring the venous plasma dissolved $\mathrm{O}_{2}$ in the $\mathrm{CMRO}_{2}$ computation, the estimated $\Delta \mathrm{CMRO}_{2}(\%)$ were $-12.7 \%$ and $-1.3 \%$ for ${ }^{\prime} \mathrm{CO}_{2}$ in air' and carbogen, respectively. When also ignoring the arterial plasma dissolved $\mathrm{O}_{2}, \Delta \mathrm{CMRO}_{2}(\%)$ was $-13.8 \%$ and $-20.6 \%$ for ' $\mathrm{CO}_{2}$ in air' and carbogen, respectively. Values for all subjects are shown in 
(a) Blood $\mathrm{O}_{2}$ content for all breathing conditions, calculated with Dash model using measured values

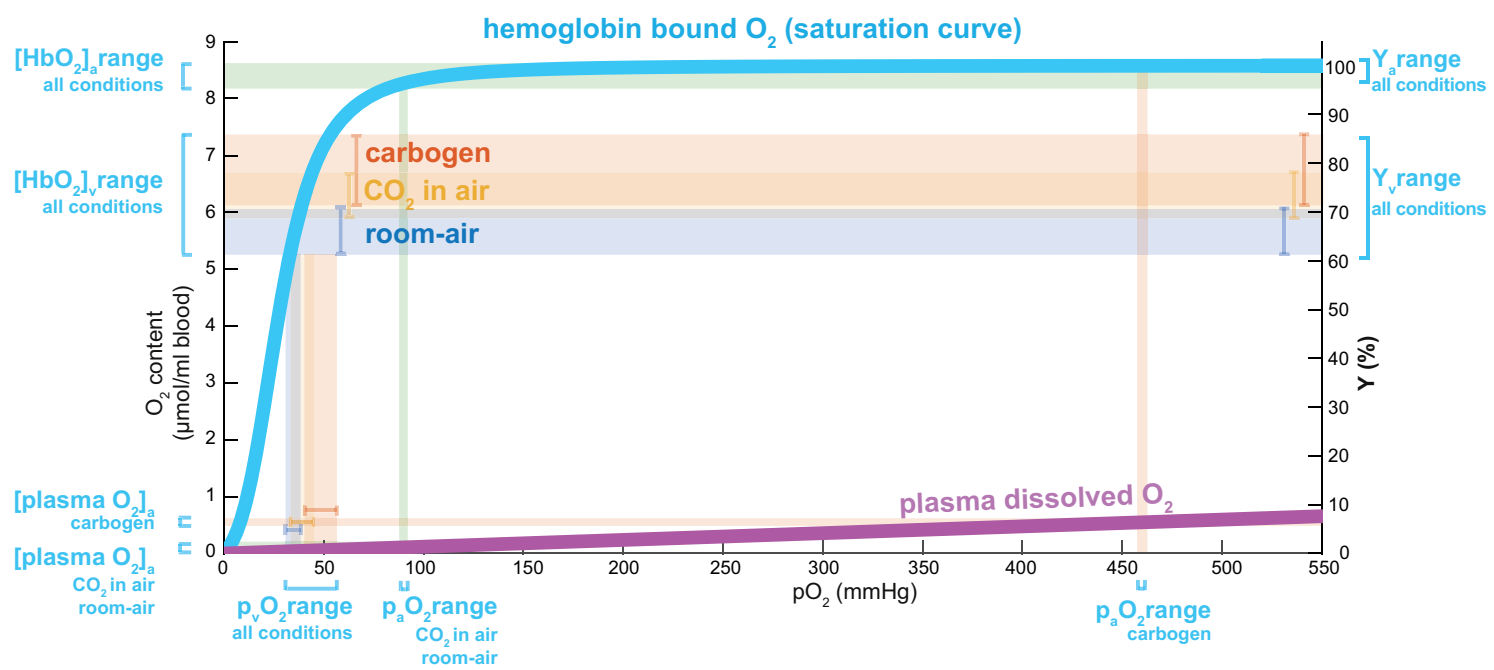

(b) Comparison of Dash model to Severinghaus curve during different breathing conditions

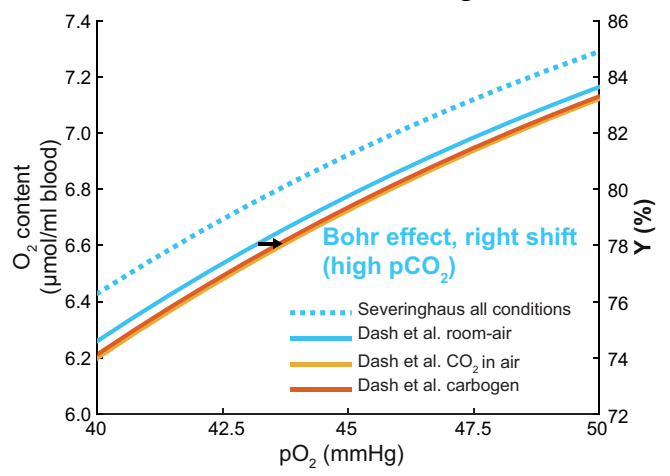

Figure 2. Oxygen saturation and content in blood for the different breathing conditions. The measured $\mathrm{pEtCO}_{2}$ values and assumed hematocrit values were used as input for the Dash et al. model to generate the subject-specific curves on saturation, hemoglobin bound and plasma dissolved $\mathrm{O}_{2}$ content over a range of $\mathrm{pO}_{2}$ between 0 and $550 \mathrm{mmHg}$. a) Group average hemoglobin bound $\mathrm{O}_{2}$ saturation curve (light blue) as computed using Dash et al. physiological model ${ }^{42}$ and the plasma dissolved $\mathrm{O}_{2}$ curve (magenta) as a function of the partial pressure of $\mathrm{O}_{2}\left(\mathrm{pO}_{2}\right)$. On the right $y$-axis, the measured ranges of hemoglobin blood oxygenation $\mathrm{Y}_{\mathrm{a}}(\%)$ and $\mathrm{Y}_{\mathrm{v}}(\%)$ for the different breathing conditions (room-air in blue, ' $\mathrm{CO}_{2}$ in air' in orange, carbogen in red, and the corresponding $\mathrm{O}_{2}$ content in $\mu \mathrm{mol} / \mathrm{ml}$ blood on the left $y$-axis $\left(\left[\mathrm{HbO}_{2}\right]_{\mathrm{a}}\right.$ and $\left[\mathrm{HbO}_{2}\right]_{\vee}$ ranges). The associated partial pressure ranges of $\mathrm{O}_{2}\left(\mathrm{p}_{v} \mathrm{O}_{2}\right.$ and $\mathrm{Pa}_{2} \mathrm{O}_{2}$ ) found via the $\mathrm{O}_{2}$ saturation curve (light blue) are shown on the x-axis. Note the high $\mathrm{paO}_{2}$ for the carbogen condition and the associated plasma dissolved $\mathrm{O}_{2}$ content shown on the bottom left (red). b) A zoomed part of the $\mathrm{O}_{2}$ saturation curve (light blue in a)) showing the traditional $\mathrm{O}_{2}$ saturation curve by Severinghaus (dotted light-blue) compared to the revised model by Dash et al. with dependency on the subject's $\mathrm{PCO}_{2}$ and Hct. The hypercapnic conditions induce a right shift caused by the Bohr effect, shown by the arrow (' $\mathrm{CO}_{2}$ in air' in orange, carbogen in red). The effect of this right shift, however, on the arteriovenous $\mathrm{O}_{2}$ difference is negligible for all breathing conditions. See Figure 3 for the $\mathrm{O}_{2}$ content and the arteriovenous difference values (boxplots) for all breathing conditions.

Supplementary Tables 1 and 2 . We performed a sensitivity analysis of variations in arterial blood water $\mathrm{T}_{1 \mathrm{a}}$ on $\mathrm{CBF}$ and $\mathrm{CMRO}_{2}$ quantification caused by, for instance, hyperoxia and Hct variations. An increase in the hyperoxic $\mathrm{T}_{1, \mathrm{HO}}$ value of $5 \%$ from the reference $\mathrm{T}_{1, \mathrm{HO}}(=1.49 \mathrm{~ms})$ leads to a decrease of $\mathrm{CBF}$ and $\mathrm{CMRO}_{2}$ of $\sim 4.0 \%$, while a $\mathrm{T}_{1, \mathrm{HO}}$ decrease of $5 \%$ leads to an increase of $\mathrm{CBF}$ and $\mathrm{CMRO}_{2}$ of $\sim 4.7 \%$ (Supplementary Figure 2). We also investigated whether different $\mathrm{T}_{1 \mathrm{a}}$ scenarios impacted the results using commonly used and recently reported $\mathrm{T}_{1, \mathrm{NO}}$ and $\mathrm{T}_{1}$, но values. The absolute $\mathrm{CBF}$ and $\mathrm{CMRO}_{2}$ results change in value as expected, however, the $\triangle \mathrm{CBF}$ and notably the $\triangle \mathrm{CMRO}_{2}$ changes did not change 


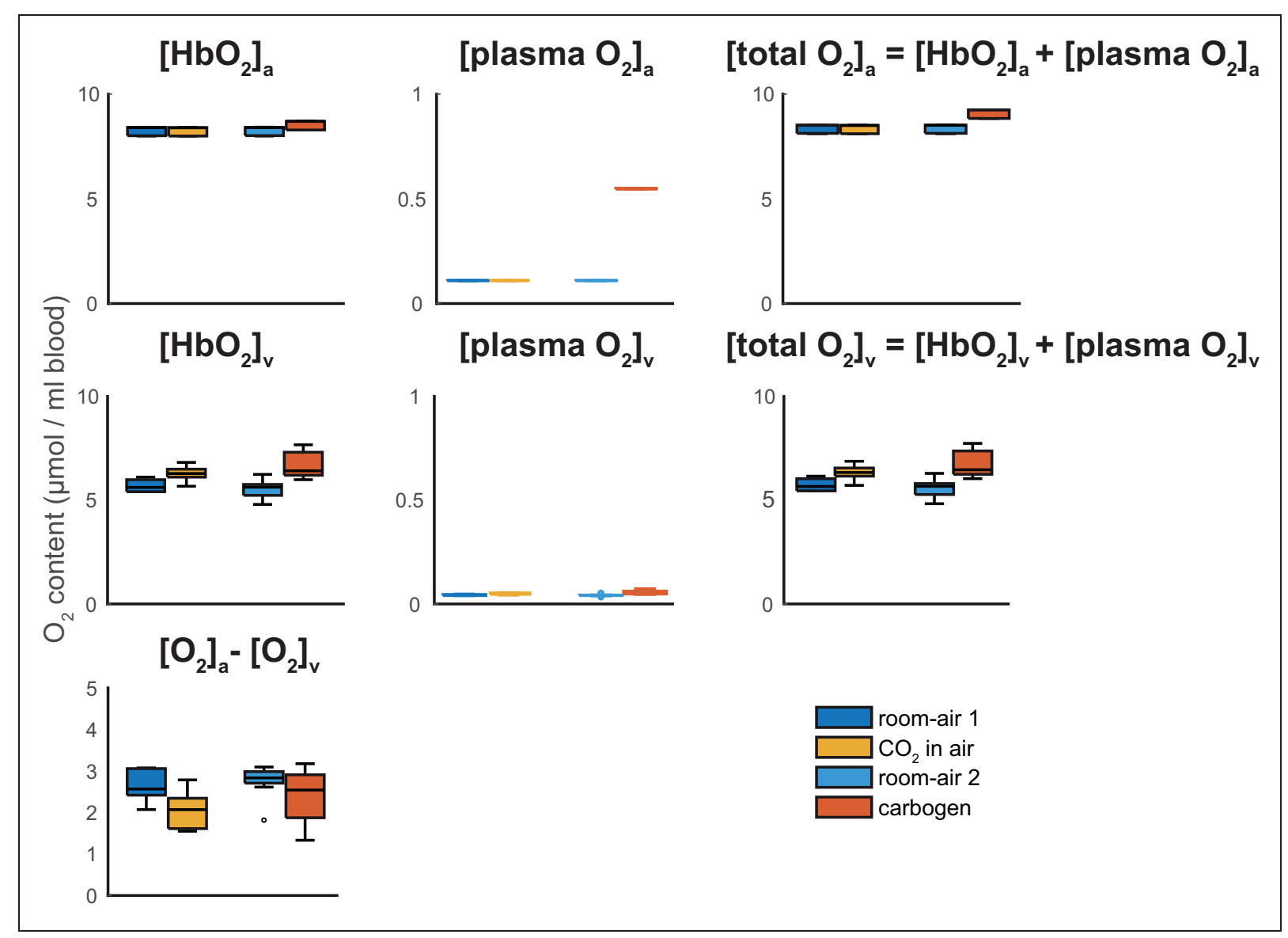

Figure 3. Boxplots showing the group average $\mathrm{O}_{2}$ content in $\mu \mathrm{mol}$ per ml blood for hemoglobin bound $\mathrm{O}_{2}$ and plasma dissolved $\mathrm{O}_{2}$ for the arterial and venous blood respectively, and the arteriovenous difference in $\mathrm{O}_{2}$ content needed to compute the $\mathrm{CMRO}_{2}$; $\left[\mathrm{HbO}_{2}\right]_{\mathrm{a}}$ and $\left[\mathrm{HbO}_{2}\right]_{v}$, [plasma $\left.\mathrm{O}_{2}\right]_{\mathrm{a}}$, and $\left[\text { plasma } \mathrm{O}_{2}\right]_{v}$, the total blood $\mathrm{O}_{2}$ content $\left[\mathrm{O}_{2}\right]_{\mathrm{a}}$ and $\left[\mathrm{O}_{2}\right]_{v}$, and $\left[\mathrm{O}_{2}\right]_{\mathrm{a}}-\left[\mathrm{O}_{2}\right]_{v}$ for the different breathing conditions. Noticeable is the increased venous hemoglobin bound $\mathrm{O}_{2}\left(\left[\mathrm{HbO}_{2}\right]_{\mathrm{v}}\right)$ for the hypercapnic conditions and the much-increased plasma dissolved $\mathrm{O}_{2}$ (arterial, [plasma $\left.\mathrm{O}_{2}\right]_{\mathrm{a}}$ ) content for the carbogen condition. Also, note the much smaller $y$-axis scale for the plasma dissolved $\mathrm{O}_{2}$ content, showing that the venous plasma dissolved $\mathrm{O}_{2}$ plays a negligible role in the arteriovenous difference to compute $\mathrm{CMRO}_{2}$ for all breathing conditions. The boxplots show the minimum, maximum, median and interquartile range, open circles denote outliers.

significantly for the different $\mathrm{T}_{1}$ scenarios (Supplementary Figure 3).

\section{Discussion}

\section{Main findings}

Using a combination of quantitative $\mathrm{CBF}$ and $\mathrm{Y}_{\mathrm{v}}$ measurements along with physiological modeling based on measured arterial blood gas values, our results reinforce the notion that hypercapnia is not an iso-metabolic stimulus. Our main findings were threefold: 1) global $\mathrm{CMRO}_{2}$ reduces with normoxichypercapnia; 2) correction for changes in the oxygen saturation curve due to hypercapnia did not significantly affect the calculation of global $\mathrm{CMRO}_{2} ; 3$ ) inhalation of carbogen gas appears to elicit a mixed effect where the reduction in $\mathrm{CMRO}_{2}$ seen during normoxichypercapnia is mitigated with the inclusion of a hyperoxic stimulus.

Our results showed that the inspiration of $5 \% \mathrm{CO}_{2}$ in room-air led to an average decrease in global $\mathrm{CMRO}_{2}$ of approximately $13.4 \%$. This falls directly in line with the $13.4 \%$ reduction reported by $\mathrm{Xu}$ et al. ${ }^{12}$ Similar findings have been reported by Thesen et al., ${ }^{18}$ who measured magnetoencephalogram responses while breathing air and a $5 \% \mathrm{CO}_{2}$ mixture and showed clear decreases in event-related field potentials under hypercapnia. ${ }^{18}$ Also, for non-human primates, a clear reduction of $\mathrm{CMRO}_{2}$ with hypercapnia has been reported. ${ }^{14,16}$

The notion that $\mathrm{CMRO}_{2}$ reductions follow a linear behavior for increasing levels of arterial $\mathrm{CO}_{2}$ forms the basis of the updated BOLD calibration model reported 


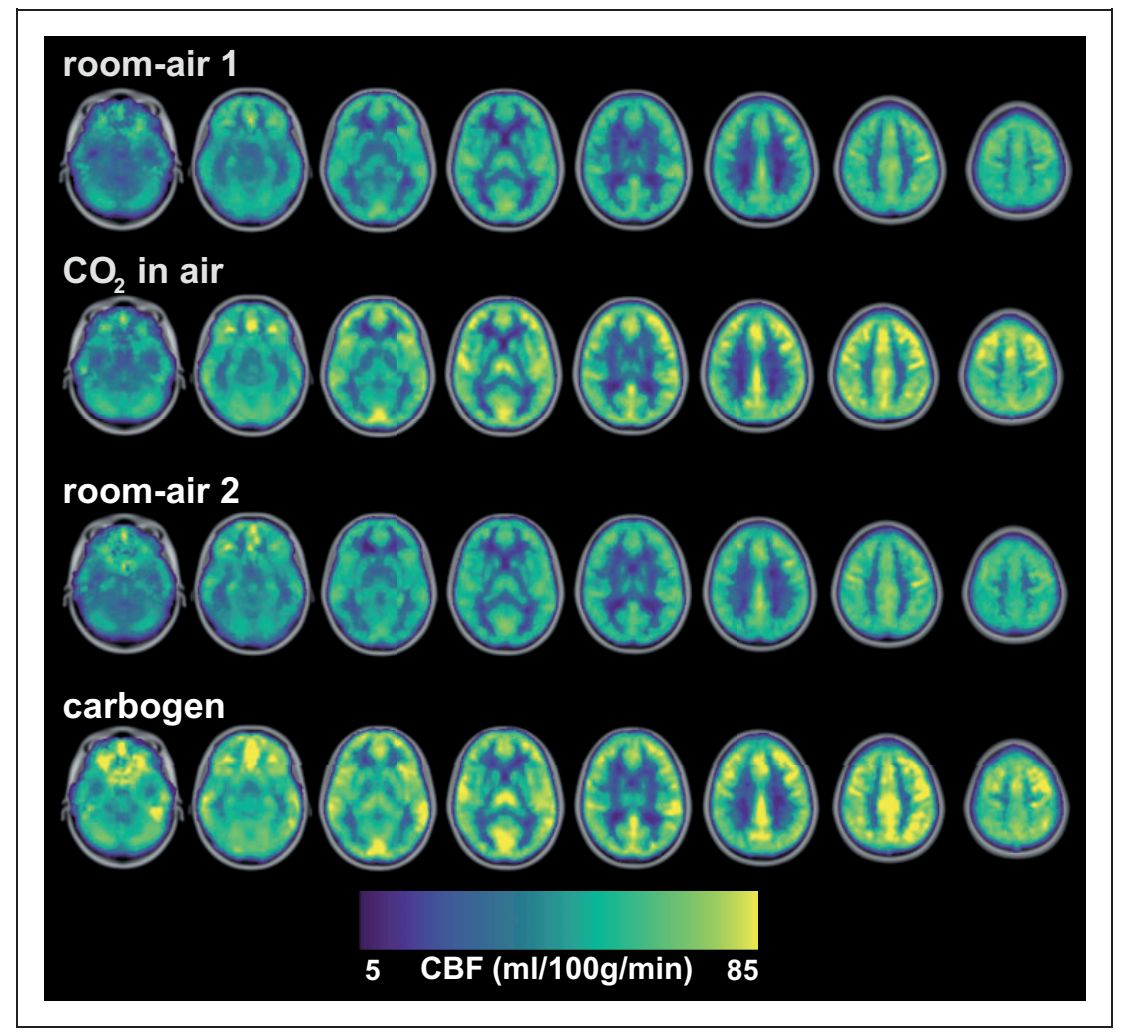

Figure 4. Group average CBF maps for the different conditions where a notable and similar increase in $\mathrm{CBF}$ is observed for ' $\mathrm{CO} \mathrm{O}_{2}$ in air' and carbogen (see also Table I). The individual maps were registered to $\mathrm{MNI}$ space before averaging and are overlaid on the $2 \mathrm{~mm}$ $\mathrm{MNI}$ brain template.

by Driver et al. ${ }^{11}$ Several reports, including those by Jain et al. ${ }^{54}$ and Chen et al., ${ }^{55}$ showed no significant difference in $\mathrm{CMRO}_{2}$ under hypercapnia. Our measured OEF values ( 0.32 for room-air, 0.25 for ' $\mathrm{CO}_{2}$ in air', and 0.26 for carbogen) were in line with previous work reported in healthy subjects using $\mathrm{ASL}^{56}$ and PET. ${ }^{46}$ The decrease in OEF for the $\mathrm{CO}_{2}$ condition can be explained by the decrease in $\mathrm{CMRO}_{2}$ and increase in $\mathrm{CBF}$, while the decrease in OEF for the carbogen condition may be (partly) attributed to the higher oxygen content in the arterial blood and the increase in $\mathrm{CBF}$.

The changes in end-tidal $\mathrm{CO}_{2}$ we observed during ' $\mathrm{CO}_{2}$ in air' $(\sim 4.2 \mathrm{mmHg})$ were lower than the 8$10 \mathrm{mmHg}$ changes typically observed in healthy subjects using a similar stimulus. Lower values may be attributed to potential gas leaking from the masks, leading to less efficient gas administration. The average baseline $\mathrm{pEtCO}_{2}$ value measured in our subjects during the room-air condition was $44.3 \pm 3.5 \mathrm{mmHg}$. These values are higher than the $\sim 40 \mathrm{mmHg}$ typically quoted in physiology textbooks and higher than what was reported by Chen et al., ${ }^{55}$ and Jain et al. ${ }^{54}$ in healthy subjects. The elevated baseline $\mathrm{CO}_{2}$ in our experiments likely stems from the fact that we used a facemask and did not clamp end-tidal gas values. This may have effectively increased dead-space, leading to more rebreathing and increased $\mathrm{pEtCO}_{2}$ as has been shown recently for the use of surgical facemasks during MRI acquisition. ${ }^{57}$ The facemask use and its effect on dead-space may also have contributed to higher room-air $Y_{v}$ values in our subjects. Our reported $Y_{\mathrm{v}}$ during the two room-air conditions, $67.3 \pm 3.6 \%$, and $65.3 \pm 5.1 \%$, however, are in line with Jain et al. ${ }^{54}$ but are higher than Chen et al. ${ }^{55}$ It should be noted that both studies reported higher increases in CBF during hypercapnia, which may account for the differences in the estimated $\mathrm{CMRO}_{2}$ change. The elevated room-air $\mathrm{pEtCO}_{2}$ that we measured could have mitigated subsequent increases in $\mathrm{pEtCO}_{2}$ due to a reduced alveolar-arterial $\mathrm{CO}_{2}$ gradient during the $\mathrm{CO}_{2}$ stimulus. For pre-dilated baseline states (due to $\mathrm{CO}_{2}$ buildup in the mask), it is conceivable that further increases in arterial $\mathrm{CO}_{2}$ may push both absolute $\mathrm{CBF}^{58,59}$ and associated $\mathrm{BOLD}^{25}$ signals when considering calibrated MRI beyond the known linear response regime. We measured an increase in CBF of approximately $1.7 \pm 1.5$ and $2.8 \pm 3.2 \mathrm{ml} / 100 \mathrm{~g} / \mathrm{min}$ per $\mathrm{mmHg}$ change in $\mathrm{pEtCO}_{2}$ during the ' $\mathrm{CO}_{2}$ in air' and carbogen conditions, respectively. These increases 


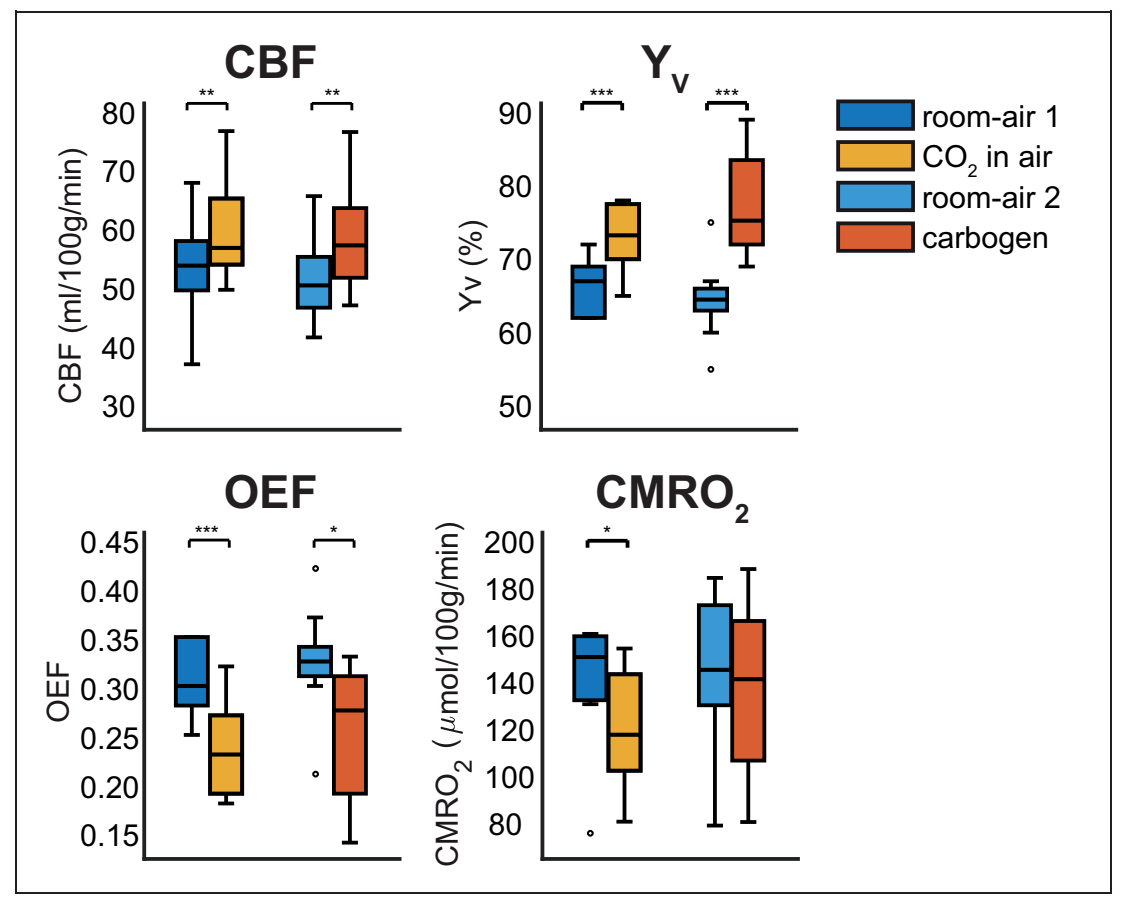

Figure 5. Boxplots showing the group average global CBF, venous oxygenation $\left(Y_{v}\right)$, computed oxygen extraction fraction (OEF), and cerebral metabolic rate of oxygen $\left(\mathrm{CMRO}_{2}\right)$ for the different conditions. Notable increases in $C B F$ and $Y_{v}$ are observed for both the ' $\mathrm{CO}_{2}$ in air' and carbogen conditions, with a more considerable $Y_{v}$ increase for the carbogen condition, as expected. A similar reduction in OEF is seen for both conditions. Only significant $\mathrm{CMRO}_{2}$ changes are observed for the ' $\mathrm{CO} \mathrm{O}_{2}$ in air' condition. The $\mathrm{CBF}$ increase for the ' $\mathrm{CO}_{2}$ in air' and carbogen conditions was not significantly different. *p-value $<0.05$ significant change found (Student's T-test) with respect to the preceding room-air condition, ${ }^{*}$ p-value $<0.005$, *** $\mathrm{p}$-value $<0.00 \mathrm{l}$. The boxplots show the minimum, maximum, median and interquartile range, open circles denote outliers.

are in line with results observed for both carbogen $(5 \%$ $\mathrm{O}_{2}$ and $95 \% \mathrm{CO}_{2}$ ) and $(5 \%) \mathrm{CO}_{2}$-enriched air inhalation in healthy volunteers. ${ }^{60}$

When measuring changes in physiological parameters in response to external stimuli, the accuracy of the stimulus delivery as well as the measurement of $\mathrm{CBF}$ and $\mathrm{Y}_{\mathrm{v}}$ is an important concern. Particularly since the data interpretation relies on physiological modeling, our methods could have benefitted from tighter control and targeting of arterial blood gases via the use of a computer-controlled gas delivery system. This could provide more accurate measurements of end-tidal $\mathrm{O}_{2}$ for more accurate estimates of blood $\mathrm{O}_{2}$ content using physiological modeling by Dash et al. $^{42}$ Also, there is the notion of adequate sensitivity; the report by $\mathrm{Xu}$ et al. ${ }^{12}$ showed that $\triangle \mathrm{CMRO}_{2}$ is proportional to $\Delta \mathrm{pEtCO}{ }_{2}$, suggesting a dose-dependent effect of $\mathrm{CO}_{2}$ on $\mathrm{CMRO}_{2}{ }^{12}$ Therefore, a sufficiently high $\Delta \mathrm{pEtCO}$ should be attained to allow significant observations of $\mathrm{CMRO}_{2}$ reductions during hypercapnia. In addition, the suggested dose-dependency of $\mathrm{CO}_{2}$ on $\Delta \mathrm{CMRO}_{2}$ would mean that discrepant $\Delta \mathrm{pEtCO}_{2}$ values will lead to discrepant $\triangle \mathrm{CMRO}_{2}$ findings. In line with this, discrepant findings on $\triangle \mathrm{CMRO}_{2}$ during hypercapnia can also be caused by differences in the duration of the hypercapnic stimulus even though similar $\Delta \mathrm{pEtCO}_{2}$ was reached. Future work on modulation of the duration of hypercapnic stimulus would shed light on this.

Assuming iso-metabolic challenges when performing calibrated BOLD experiments may lead to a systemic bias, as shown by previous simulation and experimental studies. ${ }^{10,19,20} \mathrm{~A} \quad \mathrm{CO}_{2}$-dependent reduction in $\mathrm{CMRO}_{2}$ (as has been shown in this work) would lead to an overestimation of the M-value and a concordant overestimation of the maximum possible BOLD signal change, which translates into an up to $50 \%$ overestimation in basal OEF. ${ }^{19}$ For activation-induced $\triangle \mathrm{CMRO}_{2}$ estimates, one can expect a close to linear behavior between calibration bias and the overestimation of $\triangle \mathrm{CMRO}_{2}$. This translates to a bias in the estimated OEF and $\mathrm{CMRO}_{2}$ changes $\left(\triangle \mathrm{CMRO}_{2}\right)$ during task-evoked calibrated BOLD studies. For example, Griffeth et al. $^{20}$ (see Figure $8 \mathrm{~A}$ in their report) showed that the bias in estimated $\triangle \mathrm{CMRO}_{2}$ during activation was in the range of $5 \%-10 \%$ percentage point for $10 \%-15 \%$ reduction $\mathrm{CMRO}_{2}$ during hypercapnic calibration.

Further work by Blockley et al. ${ }^{10}$ and Merola et al. ${ }^{19}$ provide a sense of how large potential errors might be due to violation of the iso-metabolic assumption. ${ }^{10,19}$ 
The effect of a non-isometabolic stimulus on CVR experiments will depend on the type of technique used. As BOLD is sensitive to changes in deoxyhemoglobin; a decrease in $\mathrm{CMRO}_{2}$ during hypercapnia could lead to an overestimation of the BOLD response and thus in an overestimation of the BOLD CVR amplitude. The size of this potential bias in BOLDCVR needs to be investigated further to see how clinically relevant this bias is. An approach to mitigate potential metabolic contamination using a hypercapnic stimulus in BOLD-CVR could be to add a hypoxic component to the gas mixture, as suggested by Peng et al. ${ }^{17}$ For ASL or ${ }^{15} \mathrm{O}-\mathrm{H}_{2} \mathrm{O}$ PET-based CVR studies, we do not expect a bias in CVR since these techniques are dominated by $\mathrm{CBF}$ changes and not sensitive to changes in deoxyhemoglobin.

The $\mathrm{CMRO}_{2}$ reported here under the room-air condition $(144.5 \pm 25.5 \mu \mathrm{mol} / 100 \mathrm{~g} / \mathrm{min})$ follows those previously reported based on TRUST-MRI, susceptibility-based $\mathrm{Y}_{\mathrm{v}}$ measurements as well as the PET goldstandard. ${ }^{46,54,61,62}$ When ignoring the venous plasma $\mathrm{O}_{2}$ for the calculation of $\Delta \mathrm{CMRO}_{2}$, this results in a 0.7 percentage point increase for the difference in $\triangle \mathrm{CMRO}_{2}$ between room-air and ' $\mathrm{CO}_{2}$ in air', the same increase was found for the difference between room-air and carbogen $\triangle \mathrm{CMRO}_{2}$. Based on these calculations, venous plasma dissolved $\mathrm{O}_{2}$ played a negligible role in the arteriovenous oxygen difference, a key factor that determines $\mathrm{CMRO}_{2}$ under the conditions assessed herein. Specifically, for the carbogen condition, arterial plasma dissolved $\mathrm{O}_{2}$ was metabolized by the tissue (see Figure 3). Arterial plasma dissolved $\mathrm{O}_{2}$ plays a negligible role in the transportation of oxygen under physiological conditions. This is reflected by the small change in $\triangle \mathrm{CMRO}_{2}$ when ignoring arterial and venous $\mathrm{O}_{2}$ for the ' $\mathrm{CO}_{2}$ in air' condition $(-13.8 \%$ compared to $-13.4 \%$ when including arterial and venous plasma dissolved $\mathrm{O}_{2}$ ). However, for carbogen, the estimated $\triangle \mathrm{CMRO}_{2}(\%)$ drastically differed when ignoring the arterial and venous plasma dissolved $\mathrm{O}_{2}(-20.6 \%$ instead of $-2.0 \%$ ). Given the very high arterial plasma $\mathrm{O}_{2}$ values seen during carbogen, this difference was expected.

The setup we used for carbogen gas inhalation is a relatively simple way to evoke a vascular response and has seen use in numerous studies. ${ }^{63-65}$ Furthermore, carbogen has been reported to be more comfortable and possibly safer for patients and participants compared to a normoxic $\mathrm{CO}_{2}$ stimulus. ${ }^{66}$ Aside from its vasodilatory action, carbogen leads to a significant increase in arterial plasma dissolved $\mathrm{O}_{2}$. Similar to the debate surrounding the effect of hypercapnia on $\mathrm{CMRO}_{2}$, the question of whether changes in arterial $\mathrm{O}_{2}$ content modulate $\mathrm{CMRO}_{2}$ has also provided mixed conclusions. Studies looking at the potential neuroprotective effect of hyperoxia for acute treatment of traumatic brain injury have reported limited changes in $\mathrm{CMRO}_{2}$ using normobaric hyperoxia. ${ }^{67}$ This finding is supported by a physiological study measuring $\mathrm{CMRO}_{2}$ during prolonged apnea using trained freedivers performed by Ainslie et al. ${ }^{68}$ Interestingly, a significant post-treatment increase in $\mathrm{CMRO}_{2}$ of $32 \%$ was observed in severe traumatic brain injury patients when applying hyperbaric hypercapnia. ${ }^{69}$ In contrast, the work of Xu et al., ${ }^{13}$ reported an $\sim 16.9 \%$ reduction in $\mathrm{CMRO}_{2}$ when breathing a normobaric fixed inspired $\mathrm{O}_{2}$ of $98 \% .{ }^{13}$ In that study, a hypoxic stimulus was reported to increase $\mathrm{CMRO}_{2}$ providing the notion that varying inspired $\mathrm{O}_{2}$ content affects $\mathrm{CMRO}_{2}$ in a dose-dependent manner. ${ }^{13}$

In the context of our work, hyperoxia seems to affect the $\mathrm{CMRO}_{2}$. If hyperoxia had a neutral effect on $\mathrm{CMRO}_{2}$, the reduction in $\mathrm{CMRO}_{2}$ seen during the ' $\mathrm{CO}_{2}$ in air' condition would carry over to the carbogen condition, which was not observed. Similarly, a further decrease in $\mathrm{CMRO}_{2}$ would have exaggerated the negative effect of hypercapnia on $\mathrm{CMRO}_{2}$. Since neither of these responses was observed in our experiments, several hypotheses could explain our finding that $\mathrm{CMRO}_{2}$ did not significantly change during the carbogen condition. The addition of the hyperoxic component seems to mitigate the hypercapnia-induced reduction in $\mathrm{CMRO}_{2}$. Here, the addition of a hyperoxic component could have altered the brain arousal state and/or the neurophysiological reactions to the hypercapnic stimulus. The notion that an interplay between hypercapnic and hyperoxic states can modulate the brain's response has been purported previously by Bain et al. ${ }^{70}$ It is important to note that while ' $\mathrm{CO}_{2}$ in air' induces a physiological condition that can be achieved naturally (i.e. being out of breath after running up several stairs, or breath-holding after hyperventilation), the effect of carbogen inhalation on blood gas composition is impossible to reach under normal circumstances. It stands to reason that accurately predicting the effect of hypercapnic-hyperoxic stimuli on $\mathrm{CMRO}_{2}$ is complex in a dynamic biological system as the human body, which has multiple mechanisms in place to actively maintain homeostasis.

\section{Considerations}

Our observation of no significant differences in CBF between the ' $\mathrm{CO}_{2}$ in air' and carbogen conditions implies that the carbogen stimulus did not lead to significant $\mathrm{O}_{2}$-mediated vasoconstriction. This is in line with previously reported MRI findings and also supports results reported using PET. ${ }^{26,45,71}$ Hyperoxia is known to modulate arterial blood water $\mathrm{T}_{1 \mathrm{a}}$ due to hyperoxia; to account for this, we incorporated a 
global $\mathrm{T}_{1, \mathrm{HO}}$ reduction in the CBF quantification as reported previously for the same carbogen stimulus, ${ }^{34}$ and investigated different $\mathrm{T}_{1 \mathrm{a}}$ scenarios (Supplementary Figure 3). It should be noted that intersubject variation will remain and will also depend on the subject's hematocrit. Any intersubject variation in $\mathrm{CBF}$ and arteriovenous $\mathrm{O}_{2}$ difference will translate directly to variation in $\mathrm{CMRO}_{2}$. From the sensitivity analysis on $T_{1}$, we observed that increasing or decreasing the hyperoxic blood water $\mathrm{T}_{1}$ by $5 \%$, $\mathrm{CBF}$ and $\mathrm{CMRO}_{2}$ increased by $4.1 \%$ or decreased by $4.7 \%$, respectively (Supplementary Figure 2). Notably, the $\triangle \mathrm{CBF}$ and $\triangle \mathrm{CMRO}_{2}$ results did not significantly change for different $T_{1 a}$ scenarios using commonly used and recently reported $\mathrm{T}_{1, \mathrm{NO}}$ and $\mathrm{T}_{1, \mathrm{HO}}$ values (Supplementary Figure 3). It is our view that for this study, inter-subject variations were likely were 'averaged out', reducing the probability of systematic bias. It is important to emphasize that our results were derived from healthy subjects, using two commonly used stimuli. Based on the presented data, it would not be accurate to extrapolate results using different $\mathrm{CO}_{2}$ with $\mathrm{O}_{2}$ gas mixture concentrations, nor can we predict responses in patients with circulatory, pulmonary, or cerebrovascular pathologies. More research is needed to investigate whether changes in $\mathrm{CMRO}_{2}$ vary with different combinations of $\mathrm{CO}_{2}$ and $\mathrm{O}_{2}$ concentrations when using carbogen-based designs. How the respective responses might change in pathological situations remains an open question.

With regards to the $Y_{v}$ measurement, the TRUST technique may exhibit a bias from hyperoxia-mediated changes in venous plasma $T_{2}$. However, we observed that the venous plasma $\mathrm{O}_{2}$ content was negligible for all conditions (Figure 3), and thus could not influence the $Y_{v}$ measurement for the carbogen condition. Furthermore, the TRUST technique relies on a single measurement taken at the occipital part of the superior sagittal sinus. While the superior sagittal sinus drains most of the total cerebral blood, it also drains the periosteum, skull, meninges, and CSF. ${ }^{44}$ Given that most of the blood flowing through the sinus is from the brain and that earlier reports on TRUST $Y_{\mathrm{v}}$ measurements at different locations have shown no difference in $\mathrm{Y}_{\mathrm{v}}{ }^{72}$ it is safe to presume the superior sagittal sinus as a representative location for a global $\mathrm{Y}_{\mathrm{v}}$ measurement. In addition, we were mainly interested in the relative change of $\mathrm{Y}_{\mathrm{v}}$ in the $\triangle \mathrm{CMRO}_{2}$ comparison for the different conditions, for which the superior sagittal sinus is appropriate under the assumption that no redistribution of blood has occurred. There are other ways than pCASL to measure global CBF, such as phase-contrast MRI. These techniques have been previously compared and showed a close match. ${ }^{55,73}$
For diagnostics, treatment, or follow-up in patients, possible regional differences in $\mathrm{CMRO}_{2}$ might be of interest to clinicians. Our approach of measuring global $Y_{\mathrm{v}}$ excludes the possibility to examine regional differences in $\mathrm{CMRO}_{2}$. Regional $\mathrm{Y}_{\mathrm{v}}$ measurements can be obtained using QSM-based techniques ${ }^{74}$ or other $\mathrm{T}_{2}$ - based MRI acquisitions, like $\mathrm{T}_{2}$-relaxationunder-phase-contrast MRI, ${ }^{75}$ Velocity Selective Excitation and Arterial Nulling ${ }^{76}$ or by using techniques based on the Asymmetric Spin Echo. ${ }^{77}$ Such approaches could further benefit from subject-specific measures of Hct or the incorporation of local Hct measures. ${ }^{78} \mathrm{We}$ assumed Hct values ( 0.42 for males, and 0.40 for females) as both the $T_{1}$ and $T_{2}$ values of blood depend on Hct. However, in healthy subjects, the Hct generally only varies by around $10 \%{ }^{51}$ it is unlikely that this would impact our $Y_{v}$ results significantly. This could be different in disease though. An earlier reported sensitivity analysis on $\mathrm{T}_{1}$ differences on TRUST $Y_{v}$ measurements demonstrated a negligible effect of slight differences in Hct on $\mathrm{Y}_{\mathrm{v}}{ }^{61}$ For our study, the incorporation of subject-specific $\mathrm{p}_{\mathrm{a}} \mathrm{CO}_{2}$ and (assumed) Hct in the model by Dash et al. ${ }^{42}$ did not impact the results dramatically (as shown in Figure 1(b)). Future (clinical) studies using such a physiological model will allow extraction of subject-specific blood oxygen content where information such as $\mathrm{p}_{\mathrm{a}} \mathrm{CO}_{2}, \mathrm{Hct}, \mathrm{pH}$, and temperature can in principle be incorporated, depending on the study design and disease of interest.

\section{Conclusion}

We found that a hypercapnic normoxic stimulus of 5\% $\mathrm{CO}_{2}$ is not necessarily iso-metabolic to room-air but leads to a decrease in $\mathrm{CMRO}_{2}$ in healthy subjects. For a hypercapnic hyperoxic stimulus as carbogen, we demonstrate that it is more iso-metabolic to room-air. Although the oxygen saturation curve is dependent on $\mathrm{p}_{\mathrm{a}} \mathrm{CO}_{2}$ (Bohr effect), amongst other parameters, correction for differences in blood $\mathrm{p}_{\mathrm{a}} \mathrm{CO}_{2}$ did not significantly influence results. We believe these findings provide valuable insight into the global hemodynamic and metabolic effects of commonly used respiratory challenges. The reported findings can be useful for future experimental designs, BOLD signal modeling, and interpreting calibrated BOLD fMRI and CVR measurements using hypercapnic or hypercapnichyperoxic (carbogen) stimuli.

\section{Funding}

The author(s) disclosed receipt of the following financial support for the research, authorship, and/or publication of this article: J.C.W.S. was supported by the National Institute of Mental Health of the National Institutes of Health under 
Award Number [R01MH111417]. P.T.D. was supported by the Brain Technology Institute [1519131] and the Friends of the UMC/WKZ foundation [1619144]. A.A.B was supported by a Dutch Research Council (NWO) funded VENI project 'The Ischemic Fingerprint' [VI. VENI.194.056]. M.B.J.D is supported by the Dutch Heart Foundation [2020T049].

\section{Declaration of conflicting interests}

The author(s) declared no potential conflicts of interest with respect to the research, authorship, and/or publication of this article.

\section{Authors' contributions}

PTD: Writing - Original Draft; Visualization; Conceptualization; Methodology

AAB: Writing - Original Draft; Conceptualization; Methodology

MBJD: Formal analysis; Writing - Review \& Editing CCF: Writing - Review \& Editing; Methodology; investigation PL: Writing - Review \& Editing; Methodology; resources

HL: Writing - Review \& Editing; Methodology; resources MJD: Resources; investigation; Methodology; Writing Review \& Editing

JCWS: Writing - Original Draft; Conceptualization; investigation; Visualization; Supervision; Formal analysis; Methodology; Project administration

\section{ORCID iDs}

Pieter T Deckers (D https://orcid.org/0000-0001-5476-547X Alex A Bhogal (D) https://orcid.org/0000-0003-3211-1760 Mathijs BJ Dijsselhof (D) https://orcid.org/0000-0001-60053110

Jeroen C.W Siero (D) https://orcid.org/0000-0001-5079-2868

\section{Supplemental material}

Supplemental material for this article is available online.

\section{References}

1. Blockley NP, Griffeth VE, Simon AB, et al. A review of calibrated blood oxygenation level-dependent (BOLD) methods for the measurement of task-induced changes in brain oxygen metabolism. NMR Biomed 2013; 26: 987-1003.

2. De Vis JB, Hendrikse J, Bhogal A, et al. Age-related changes in brain hemodynamics; a calibrated MRI study. Hum Brain Mapp 2015; 36: 3973-3987.

3. Hoge RD. Calibrated FMRI. Neuroimage 2012; 62: 930-937.

4. Davis TL, Kwong KK, Weisskoff RM, et al. Calibrated functional MRI: mapping the dynamics of oxidative metabolism. Proc Natl Acad Sci U S A 1998; 95: 1834-1839.

5. De Vis JB, Petersen ET, Bhogal A, et al. Calibrated MRI to evaluate cerebral hemodynamics in patients with an internal carotid artery occlusion. J Cereb Blood Flow Metab 2015; 35: 1015-1023.
6. Liu P, De Vis JB and Lu H. Cerebrovascular reactivity (CVR) MRI with $\mathrm{CO} 2$ challenge: a technical review. Neuroimage 2019; 187: 104-115.

7. Gauthier CJ and Hoge RD. Magnetic resonance imaging of resting $\mathrm{OEF}$ and $\mathrm{CMRO}(2)$ using a generalized calibration model for hypercapnia and hyperoxia. Neuroimage 2012; 60: 1212-1225.

8. Wise RG, Harris AD, Stone AJ, et al. Measurement of OEF and absolute CMRO2: MRI-based methods using interleaved and combined hypercapnia and hyperoxia. Neuroimage 2013; 83: 135-147.

9. Bulte DP, Kelly M, Germuska M, et al. Quantitative measurement of cerebral physiology using respiratorycalibrated MRI. Neuroimage 2012; 60: 582-591.

10. Blockley NP, Griffeth VE, Stone AJ, et al. Sources of systematic error in calibrated BOLD based mapping of baseline oxygen extraction fraction. Neuroimage 2015; 122: 105-113.

11. Driver ID, Wise RG and Murphy K. Graded hypercapnia-calibrated BOLD: beyond the isometabolic hypercapnic assumption. Front Neurosci 2017; 11: 276.

12. Xu F, Uh J, Brier MR, et al. The influence of carbon dioxide on brain activity and metabolism in conscious humans. J Cereb Blood Flow Metab 2011; 31: 58-67.

13. Xu F, Liu P, Pascual JM, et al. Effect of hypoxia and hyperoxia on cerebral blood flow, blood oxygenation, and oxidative metabolism. J Cereb Blood Flow Metab 2012; 32: 1909-1918.

14. Zappe AC, Uludağ K, Oeltermann A, et al. The influence of moderate hypercapnia on neural activity in the anesthetized nonhuman primate. Cereb Cortex 2008; 18: 2666-2673.

15. Driver ID, Whittaker JR, Bright MG, et al. Arterial $\mathrm{CO}_{2}$ fluctuations modulate neuronal rhythmicity: Implications for MEG and fMRI studies of Resting-State networks. J Neurosci 2016; 36: 8541-8550.

16. Kliefoth AB, Grubb RL Jr and Raichle ME. Depression of cerebral oxygen utilization by hypercapnia in the rhesus monkey. J Neurochem 1979; 32: 661-663.

17. Peng SL, Ravi H, Sheng M, et al. Searching for a truly "iso-metabolic" gas challenge in physiological MRI. J Cereb Blood Flow Metab 2017; 37: 715-725.

18. Thesen T, Leontiev O, Song T, et al. Depression of cortical activity in humans by mild hypercapnia. Hum Brain Mapp 2012; 33: 715-726.

19. Merola A, Murphy K, Stone AJ, et al. Measurement of oxygen extraction fraction (OEF): an optimized BOLD signal model for use with hypercapnic and hyperoxic calibration. Neuroimage 2016; 129: 159-174.

20. Griffeth VE and Buxton RB. A theoretical framework for estimating cerebral oxygen metabolism changes using the calibrated-BOLD method: modeling the effects of blood volume distribution, hematocrit, oxygen extraction fraction, and tissue signal properties on the BOLD signal. Neuroimage 2011; 58: 198-212.

21. Lu HZ and Ge YL. Quantitative evaluation of oxygenation in venous vessels using T2-relaxation-underspin-tagging MRI. Magn Reson Med 2008; 60: 357-363. 
22. Jespersen SN and Ostergaard L. The roles of cerebral blood flow, capillary transit time heterogeneity, and oxygen tension in brain oxygenation and metabolism. J Cereb Blood Flow Metab 2012; 32: 264-277.

23. Baez-Yanez MG, Ehses P, Mirkes C, et al. The impact of vessel size, orientation and intravascular contribution on the neurovascular fingerprint of BOLD bSSFP fMRI. Neuroimage 2017; 163: 13-23.

24. Faraco CC, Strother MK, Siero JC, et al. The cumulative influence of hyperoxia and hypercapnia on blood oxygenation and R*(2). J Cereb Blood Flow Metab 2015; 35 : 2032-2042.

25. Bhogal AA, Siero JC, Fisher JA, et al. Investigating the non-linearity of the BOLD cerebrovascular reactivity response to targeted hypo/hypercapnia at 7T. Neuroimage 2014; 98: 296-305.

26. Champagne AA, Bhogal AA, Coverdale NS, et al. A novel perspective to calibrate temporal delays in cerebrovascular reactivity using hypercapnic and hyperoxic respiratory challenges. Neuroimage 2019; 187: 154-165.

27. Duffin J, Sobczyk O, McKetton L, et al. Cerebrovascular resistance: the basis of cerebrovascular reactivity. Front Neurosci 2018; 12: 409.

28. Bhogal AA, De Vis JB, Siero JCW, et al. The BOLD cerebrovascular reactivity response to progressive hypercapnia in young and elderly. Neuroimage 2016; 139: 94-102.

29. Donahue MJ, Faraco CC, Strother MK, et al. Bolus arrival time and cerebral blood flow responses to hypercarbia. J Cereb Blood Flow Metab 2014; 34: 1243-1252.

30. Liu P, Xu F and Lu H. Test-retest reproducibility of a rapid method to measure brain oxygen metabolism. Magn Reson Med 2013; 69: 675-681.

31. Xu F, Uh J, Liu P, et al. On improving the speed and reliability of T2-relaxation-under-spin-tagging (TRUST) MRI. Magn Reson Med 2012; 68: 198-204.

32. Chappell MA, Groves AR, Whitcher B, et al. Variational bayesian inference for a nonlinear forward model. Ieee Trans Signal Process 2009; 57: 223-236.

33. Buxton RB, Frank LR, Wong EC, et al. A general kinetic model for quantitative perfusion imaging with arterial spin labeling. Magn Reson Med 1998; 40: 383-396.

34. Siero JC, Strother MK, Faraco CC, et al. In vivo quantification of hyperoxic arterial blood water T1. NMR Biomed 2015; 28: 1518-1525.

35. Rooney WD, Johnson G, Li X, et al. Magnetic field and tissue dependencies of human brain longitudinal $1 \mathrm{H} 2 \mathrm{O}$ relaxation in vivo. Magn Reson Med 2007; 57: 308-318.

36. Juttukonda MR, Li B, Almaktoum R, et al. Characterizing cerebral hemodynamics across the adult lifespan with arterial spin labeling MRI data from the human connectome Project-Aging. Neuroimage 2021; 230: 117807 .

37. Zhang Y, Brady M and Smith S. Segmentation of brain MR images through a hidden markov random field model and the expectation-maximization algorithm. IEEE Trans Med Imaging 2001; 20: 45-57.

38. Mazziotta J, Toga A, Evans A, et al. A probabilistic atlas and reference system for the human brain: International consortium for brain mapping (ICBM). philosophical transactions of the. Royal Society of London Series B, Biological Sciences 2001; 356: 1293-1322.

39. Jenkinson M, Beckmann CF, Behrens TE, et al. Fsl. Neuroimage 2012; 62: 782-790.

40. Smith SM. Fast robust automated brain extraction. Hum Brain Mapp 2002; 17: 143-155.

41. Jenkinson M and Smith S. A global optimisation method for robust affine registration of brain images. Med Image Anal 2001; 5: 143-156.

42. Dash RK, Korman B and Bassingthwaighte JB. Simple accurate mathematical models of blood $\mathrm{HbO} 2$ and $\mathrm{HbCO} 2$ dissociation curves at varied physiological conditions: evaluation and comparison with other models. Eur J Appl Physiol 2016; 116: 97-113.

43. Collins JA, Rudenski A, Gibson J, et al. Relating oxygen partial pressure, saturation and content: the haemoglobin-oxygen dissociation curve. Breathe (Sheffield, England) 2015; 11: 194-201.

44. Hall JE and Guyton AC. Guyton and hall textbook of medical physiology. Saunders Elsevier. 2010. 12th edition.

45. Ashkanian M, Gjedde A, Mouridsen K, et al. Carbogen inhalation increases oxygen transport to hypoperfused brain tissue in patients with occlusive carotid artery disease: increased oxygen transport to hypoperfused brain. Brain Res 2009; 1304: 90-95.

46. Ashkanian M, Borghammer P, Gjedde A, et al. Improvement of brain tissue oxygenation by inhalation of carbogen. Neuroscience 2008; 156: 932-938.

47. Lu H, Clingman C, Golay X, et al. Determining the longitudinal relaxation time (T1) of blood at 3.0 tesla. Magn Reson Med 2004; 52: 679-682.

48. Alsop DC, Detre JA, Golay X, et al. Recommended implementation of arterial spin-labeled perfusion MRI for clinical applications: a consensus of the ISMRM perfusion study group and the european consortium for ASL in dementia. Magn Reson Med 2015; 73: 102-116.

49. Pilkinton DT, Hiraki T, Detre JA, et al. Absolute cerebral blood flow quantification with pulsed arterial spin labeling during hyperoxia corrected with the simultaneous measurement of the longitudinal relaxation time of arterial blood. Magn Reson Med 2012; 67: 1556-1565.

50. Germuska M, Chandler HL, Stickland RC, et al. Dualcalibrated fMRI measurement of absolute cerebral metabolic rate of oxygen consumption and effective oxygen diffusivity. Neuroimage 2019; 184: 717-728.

51. Li W, Grgac K, Huang A, et al. Quantitative theory for the longitudinal relaxation time of blood water. Magn Reson Med 2016; 76: 270-281.

52. Li W, Liu P, Lu H, et al. Fast measurement of blood T1 in the human carotid artery at 3T: accuracy, precision, and reproducibility. Magn Reson Med 2017; 77: 2296-2302.

53. Ma Y, Berman AJ and Pike GB. The effect of dissolved oxygen on the relaxation rates of blood plasma: Implications for hyperoxia calibrated BOLD. Magn Reson Med 2016; 76: 1905-1911.

54. Jain V, Langham MC, Floyd TF, et al. Rapid magnetic resonance measurement of global cerebral metabolic rate 
of oxygen consumption in humans during rest and hypercapnia. J Cereb Blood Flow Metab 2011; 31: 1504-1512.

55. Chen JJ and Pike GB. Global cerebral oxidative metabolism during hypercapnia and hypocapnia in humans: implications for BOLD fMRI. J Cereb Blood Flow Metab 2010; 30: 1094-1099.

56. An H, Sen S, Chen Y, et al. Noninvasive measurements of cerebral blood flow, oxygen extraction fraction, and oxygen metabolic index in human with inhalation of air and carbogen using magnetic resonance imaging. Transl Stroke Res 2012; 3: 246-254.

57. Law CSW, Lan PS and Glover GH. Effect of wearing a face mask on fMRI BOLD contrast. Neuroimage 2021; 229: 117752.

58. Battisti-Charbonney A, Fisher J and Duffin J. The cerebrovascular response to carbon dioxide in humans. J Physiol 2011; 589: 3039-3048.

59. Halani S, Kwinta JB, Golestani AM, et al. Comparing cerebrovascular reactivity measured using BOLD and cerebral blood flow MRI: the effect of basal vascular tension on vasodilatory and vasoconstrictive reactivity. Neuroimage 2015; 110: 110-123.

60. Hare HV, Germuska M, Kelly ME, et al. Comparison of $\mathrm{CO}_{2}$ in air versus carbogen for the measurement of cerebrovascular reactivity with magnetic resonance imaging. J Cereb Blood Flow Metab 2013; 33: 1799-1805.

61. Xu F, Ge Y and Lu H. Noninvasive quantification of whole-brain cerebral metabolic rate of oxygen (CMRO2) by MRI. Magn Reson Med 2009; 62: 141-148.

62. Yamaguchi T, Kanno I, Uemura K, et al. Reduction in regional cerebral metabolic rate of oxygen during human aging. Stroke 1986; 17: 1220-1228.

63. Gauthier CJ, Madjar C, Tancredi FB, et al. Elimination of visually evoked BOLD responses during carbogen inhalation: implications for calibrated MRI. Neuroimage 2011; 54: 1001-1011.

64. Faraco CC, Strother MK, Dethrage LM, et al. Dual echo vessel-encoded ASL for simultaneous BOLD and CBF reactivity assessment in patients with ischemic cerebrovascular disease. Magn Reson Med 2015; 73: 1579-1592.

65. Chakhoyan A, Corroyer-Dulmont A, Leblond MM, et al. Carbogen-induced increases in tumor oxygenation depend on the vascular status of the tumor: a multiparametric MRI study in two rat glioblastoma models. J Cereb Blood Flow Metab 2017; 37: 2270-2282.

66. Donahue MJ, Dethrage LM, Faraco CC, et al. Routine clinical evaluation of cerebrovascular reserve capacity using carbogen in patients with intracranial stenosis. Stroke 2014; 45: 2335-2341.
67. Diringer MN, Aiyagari V, Zazulia AR, et al. Effect of hyperoxia on cerebral metabolic rate for oxygen measured using positron emission tomography in patients with acute severe head injury. Jns 2007; 106: 526-529.

68. Ainslie PN, Shaw AD, Smith KJ, et al. Stability of cerebral metabolism and substrate availability in humans during hypoxia and hyperoxia. Clin Sci (Lond) 2014; 126: $661-670$.

69. Rockswold SB, Rockswold GL, Zaun DA, et al. A prospective, randomized clinical trial to compare the effect of hyperbaric to normobaric hyperoxia on cerebral metabolism, intracranial pressure, and oxygen toxicity in severe traumatic brain injury. Jns 2010; 112: 1080-1094.

70. Bain AR, Ainslie PN, Hoiland RL, et al. Cerebral oxidative metabolism is decreased with extreme apnoea in humans; impact of hypercapnia. J Physiol 2016; 594: 5317-5328.

71. Croal PL, Hall EL, Driver ID, et al. The effect of isocapnic hyperoxia on neurophysiology as measured with MRI and MEG. Neuroimage 2015; 105: 323-331.

72. Liu P, Dimitrov I, Andrews T, et al. Multisite evaluations of a T2 -relaxation-under-spin-tagging (TRUST) MRI technique to measure brain oxygenation. Magn Reson Med 2016; 75: 680-687.

73. Dolui S, Wang Z, Wang DJJ, et al. Comparison of noninvasive MRI measurements of cerebral blood flow in a large multisite cohort. J Cereb Blood Flow Metab 2016; 36: 1244-1256.

74. Fan AP, Khalil AA, Fiebach JB, et al. Elevated brain oxygen extraction fraction measured by MRI susceptibility relates to perfusion status in acute ischemic stroke. J Cereb Blood Flow Metab 2020; 40: 539-551.

75. Krishnamurthy LC, Liu P, Ge Y, et al. Vessel-specific quantification of blood oxygenation with T2-relaxationunder-phase-contrast MRI. Magn Reson Med 2014; 71: 978-989.

76. Liu EY, Guo J, Simon AB, et al. The potential for gasfree measurements of absolute oxygen metabolism during both baseline and activation states in the human brain. Neuroimage 2020; 207: 116342.

77. Yin Y, Shu S, Qin L, et al. Effects of mild hypoxia on oxygen extraction fraction responses to brain stimulation. J Cereb Blood Flow Metab 2021; 41: 2216-2228.

78. Calamante F, Ahlgren A, van Osch MJ, et al. A novel approach to measure local cerebral haematocrit using MRI. J Cereb Blood Flow Metab 2016; 36: 768-780. 